OPEN ACCESS

Edited by: Hansen Wang University of Toronto, Canada

Reviewed by: Fidel Santamaria, University of Texas at San Antonio,

Masanobu Kano, University of Tokyo, Japan

*Correspondence: Filippo Tempia filippo.tempia@unito.it

Received: 10 July 2016 Accepted: 19 October 2016 Published: 03 November 2016

Citation: Hoxha E, Tempia F, Lippiello P and Miniaci MC (2016) Modulation, Plasticity and Pathophysiology of the Parallel Fiber-Purkinje Cell Synapse. Front. Synaptic Neurosci. 8:35. doi: 10.3389/fnsyn.2016.00035

\section{Modulation, Plasticity and Pathophysiology of the Parallel Fiber-Purkinje Cell Synapse}

\author{
Eriola Hoxha ${ }^{1}$, Filippo Tempia ${ }^{1 *}$, Pellegrino Lippiello ${ }^{2}$ and Maria Concetta Miniaci ${ }^{2}$ \\ ${ }^{1}$ Neuroscience Institute Cavalieri Ottolenghi (NICO) and Department of Neuroscience, University of Torino, Torino, Italy, \\ ${ }^{2}$ Department of Pharmacy, University of Naples Federico II, Naples, Italy
}

The parallel fiber-Purkinje cell (PF-PC) synapse represents the point of maximal signal divergence in the cerebellar cortex with an estimated number of about 60 billion synaptic contacts in the rat and 100,000 billions in humans. At the same time, the Purkinje cell dendritic tree is a site of remarkable convergence of more than 100,000 parallel fiber synapses. Parallel fiber activity generates fast postsynaptic currents via $\alpha$-amino3-hydroxy-5-methyl-4-isoxazolepropionic acid (AMPA) receptors, and slower signals, mediated by $\mathrm{mGlu}_{1}$ receptors, resulting in Purkinje cell depolarization accompanied by sharp calcium elevation within dendritic regions. Long-term depression (LTD) and long-term potentiation (LTP) have been widely described for the PF-PC synapse and have been proposed as mechanisms for motor learning. The mechanisms of induction for LTP and LTD involve different signaling mechanisms within the presynaptic terminal and/or at the postsynaptic site, promoting enduring modification in the neurotransmitter release and change in responsiveness to the neurotransmitter. The PF-PC synapse is finely modulated by several neurotransmitters, including serotonin, noradrenaline and acetylcholine. The ability of these neuromodulators to gate LTP and LTD at the PF-PC synapse could, at least in part, explain their effect on cerebellar-dependent learning and memory paradigms. Overall, these findings have important implications for understanding the cerebellar involvement in a series of pathological conditions, ranging from ataxia to autism. For example, PF-PC synapse dysfunctions have been identified in several murine models of spino-cerebellar ataxia (SCA) types 1, 3, 5 and 27. In some cases, the defect is specific for the AMPA receptor signaling (SCA27), while in others the mGlu 1 pathway is affected (SCA1, 3, 5). Interestingly, the PF-PC synapse has been shown to be hyper-functional in a mutant mouse model of autism spectrum disorder, with a selective deletion of Pten in Purkinje cells. However, the full range of methodological approaches, that allowed the discovery of the physiological principles of PF-PC synapse function, has not yet been completely exploited to investigate the pathophysiological mechanisms of diseases involving the cerebellum. We, therefore, propose to extend the spectrum of experimental investigations to tackle this problem.

Keywords: Purkinje cell, parallel fiber, synaptic plasticity, synaptic modulation, ataxia, AMPA receptor, mGlu receptor 


\section{INTRODUCTION}

While the physiological mechanisms of the parallel fiber-Purkinje cell (PF-PC) synapse are known in detail and its plasticity has been investigated in depth, the role, mechanisms and consequences of cerebellar neuromodulation are not completely known. Moreover, the pathophysiology of diseases caused by cerebellar dysfunction are only starting to be investigated, and the full spectrum of physiological methodologies has not yet been applied to these studies. This review is aimed at integrating the current knowledge about PF-PC synapse physiology, including its modulation, to help researchers to face the problem of the mechanisms responsible for cerebellum-dependent diseases including ataxia. In addition, we propose novel suggestions about new lines of research aimed at assessing the mechanisms of cerebellar involvement in autism.

\section{PHYSIOLOGICAL PROPERTIES OF THE PARALLEL FIBER-PURKINJE CELL SYNAPSE}

The PF-PC synapse is the site of the greatest signal divergence in the cerebellar system. The afferent mossy fibers convey to the cerebellar cortex an enormous number of input signals representing almost every kind of information processed by the central nervous system. Each mossy fiber distributes signals to about 500 granule cells (Ito, 1984, 2006). Granule cells are the most abundant neuronal type in the central nervous system, with an estimated number of $92 \times 10^{6}$ in the rat (Harvey and Napper, 1988) and $69 \times 10^{9}$ neurons in the human cerebellum (Azevedo et al., 2009). Granule cell axons ascend toward the pial surface, and bifurcate in a T-shaped manner, giving rise to PFs. These fibers run in the transverse plane, along the major axis of a folium. In the rat cerebellum, PFs excite PC dendrites along an extension of about $3 \mathrm{~mm}$ (Arata and Ito, 2004; Ito, 2006). In the same animal species, it has been calculated that each PF forms about 300 en passant synapses with PCs (Palay and ChanPalay, 1974; Ito, 2006). Thus, in the rat cerebellum, the signals originating from a single mossy fiber are distributed to about 150,000 PCs.

At the end of such a signal divergence, there is a massive convergence since each PC receives signals from more than 100,000 PFs (in the rat about 175,000; Napper and Harvey, 1988). For this reason, the extensive dendritic tree of PCs can be compared to a huge bidimensional matrix with more than 100,000 elements, one for each PF synaptic contact. The total number of PF-PC synaptic contacts in the whole cerebellum of rat corresponds to about $60 \times 10^{9}$ (Huang et al., 2014). Concerning the human cerebellum, the number of PF-PC synaptic contacts can be estimated to be around $10^{14}$ (Azevedo et al., 2009; Huang et al., 2014). A series of theories concerning signal processing in the cerebellar cortex are based on the selection and fine tuning of this enormous variety of signals at the level of each single PF-PC contact (Marr, 1969; Albus, 1971; Schweighofer, 1998; D’Angelo et al., 2016).
In contrast to such richness of signals distributed by PFs, each $\mathrm{PC}$ receives inputs from a single climbing fiber (CF), which generates a powerful postsynaptic depolarization, giving rise to a brief train of action potentials, which together constitute the "complex spike". The complex spike is associated with a large rise in intradendritic calcium $\left(\mathrm{Ca}^{2+}\right)$ concentration (Konnerth et al., 1992; Miyakawa et al., 1992). Most theories of cerebellar function are based on the coincidence of PF-PC signals with the activity arriving via the CF (Marr, 1969; Albus, 1971; Ito, 1982, 2001). The time window for dynamic and plastic phenomena is further shaped by local inhibitory interneurons (Scelfo et al., 2008; Ramakrishnan et al., 2016). Thus, the modulation of PF-PC synapses and their short and long-term plasticity, together with PC intrinsic plasticity, are the crucial determinants of the way PCs process incoming signals to generate the output leaving the cerebellar cortex via their axons. In fact, PC axons are the sole efferent fibers from the cortex to the deep cerebellar nuclei (DCN), with the final effect of adding a contribution to a large variety of signals traveling in the central nervous system, including motor commands, cognitive, emotional, visceral and sensory information (for review see D’Angelo and Casali, 2013).

\section{The Parallel Fiber-AMPA-EPSC}

The principal signal generated by glutamate released by PFs is a brief depolarization due to an excitatory post-synaptic current (EPSC) though postsynaptic glutamate receptors of the $\alpha$-amino-3-hydroxy-5-methyl-4-isoxazolepropionic acid (AMPA) type, formed by subunits GluA1-4 (Tempia et al., 1996). The influx of $\mathrm{Ca}^{2+}$ through these receptors is negligible, as it has been measured to constitute about $0.6 \%$ of the total inward current. This means that, under physiological conditions, PC AMPA receptors are strongly selective for monovalent cations, such as sodium and potassium ions. The exclusion of $\mathrm{Ca}^{2+}$ ions from the selectivity filter is due to the presence of an arginine residue $(R)$ in a critical position called $Q / R$ site. The mechanism that allows PC AMPA receptors to have an $\mathrm{R}$ residue is peculiar, because all four genes of AMPA receptor subunits, GluA1, 2, 3 and 4, code for a glutamine (Q) residue (Hollmann et al., 1991; Hume et al., 1991). However, the GluA2 subunit undergoes an mRNA editing process, which converts a Q-coding triplet into and R-coding one (Sommer et al., 1991). In cerebellar PCs the efficiency of the editing process is almost $100 \%$, as can be inferred by the negligible $\mathrm{Ca}^{2+}$ permeability of AMPA receptors. In addition to a complete editing of the GluA2 mRNA, a strong expression of this subunit is also necessary, so that virtually all AMPA receptors, which are tetramers, contain at least one $R$ in the selectivity filter, which is sufficient to exclude $\mathrm{Ca}^{2+}$. This is the case in PCs.

It is interesting to note that the majority of PF-PC synapses have been shown to be silent but this has a series of advantages (Ekerot and Jörntell, 2001; Isope and Barbour, 2002). First, simulation studies using a perceptron neural network model have shown that the presence of $50 \%$ silent PF-PC synapses optimizes the information storage in terms of reliability and capacity (Brunel et al., 2004). Second, even if most PF-PC synapses are silent, the remaining synapses show 
a high release probability with only a few failures (Isope and Barbour, 2002). Third, PFs have a fast vesicle replenishment rate (Valera et al., 2012), which allows the active granule cells to transmit signals to PC with high efficiency and reliability (Isope and Barbour, 2002; Valera et al., 2012). These functional features endow the PF-PC synapse to sustain very high firing frequencies, up to $1 \mathrm{kHz}$, which are generated in bursts of activity during physiological stimulation in vivo (Eccles et al., 1966; Chadderton et al., 2004; van Beugen et al., 2013). In such a way PF-PC synapses can guarantee a high fidelity transmission even at high frequencies (Isope and Barbour, 2002; Valera et al., 2012), but also assure a linear transfer function for frequencies up to $300 \mathrm{~Hz}$ (van Beugen et al., 2013).

\section{The Parallel Fiber-mGlu 1 -EPSC}

In addition to AMPA receptors located in front of the presynaptic active zone from which glutamate is released, PC dendritic spines innervated by PFs also express $\mathrm{mGlu}_{1}$ G-protein coupled receptors, localized perisynaptically (Nusser et al., 1994). As a consequence of their location, more distant from the release site, and because of the high efficiency of glutamate reuptake mechanisms (Takahashi et al., 1995), isolated action potentials are not effective for the activation of $\mathrm{mGlu}_{1}$ receptors, but a brief train of $\mathrm{PF}$ action potentials is required, so that glutamate concentration can build up in the synaptic cleft and diffuse to the perisynaptic zone. The activation of $\mathrm{mGlu}_{1}$ receptors generates a localized increase of $\mathrm{Ca}^{2+}$ in a portion of the dendritic tree (Finch and Augustine, 1998; Takechi et al., 1998; Tempia et al., 2001), accompanied by an excitatory post-synaptic potential (Batchelor and Garthwaite, 1993; Batchelor et al., 1994).

The mechanism responsible for the $\mathrm{mGlu}_{1}$-dependent intradendritic $\mathrm{Ca}^{2+}$ signal is the canonical transduction pathway. The resulting $\mathrm{Ca}^{2+}$ signal is independent of the membrane potential because it is generated by the release of $\mathrm{Ca}^{2+}$ from the endoplasmic reticulum (Finch and Augustine, 1998; Takechi et al., 1998; Tempia et al., 2001). The $\mathrm{mGlu}_{1}$ receptor activates a $\mathrm{G}_{\mathrm{q}}$ protein, which activates phospholipase $\mathrm{C}$ (PLC), starting the production of diacylglycerol (DAG) and inositol 1,4, 5-trisphosphate $\left(\mathrm{IP}_{3}\right) . \mathrm{IP}_{3}$ opens $\mathrm{Ca}^{2+}$ release channels $\left(\mathrm{IP}_{3}\right.$ receptors: $\mathrm{IP}_{3} \mathrm{Rs}$ ) in the endoplasmic reticulum. The coincident activation of $\mathrm{PF}$ leading to $\mathrm{Ca}^{2+}$ release, and $\mathrm{CF}$, causing $\mathrm{Ca}^{2+}$ entry through voltage-gated channels, is considered a critical signal to trigger synaptic plasticity (Tempia and Konnerth, 1994).

The excitatory post-synaptic potential evoked by the activation of $\mathrm{mGlu}_{1}$ receptors (Batchelor and Garthwaite, 1993; Batchelor et al., 1994) is due to an inward current (PF-mGlu ${ }_{1}$-EPSC; Tempia et al., 1998). The PF-mGlu ${ }^{-}$ EPSC has an amplitude and a duration, which encode the frequency and the number of PF action potentials (Tempia et al., 1998). The latency of the PF-mGlu ${ }_{1}$-EPSC is in the subsecond range, relatively short for a $G$ protein-mediated process, with the smallest value of $0.14 \mathrm{~s}$ (Tempia et al., 1998). The transduction pathway leading to the PF-mGlu $u_{1}$ EPSC is an unconventional one. PCs selectively express G proteins of the $\mathrm{G}_{\mathrm{q}}$ subclass (Tanaka et al., 2000), and more precisely $\mathrm{G}_{\mathrm{q}}$ and $\mathrm{G}_{\text {alphall }}$ (Tanaka et al., 2000). Among these two proteins, only $G_{q}$ is required for the generation of PF-mGlu ${ }_{1}$-EPSC (Hartmann et al., 2004); but its downstream pathway leading to the activation of PLC, $\mathrm{IP}_{3}$ or protein kinase $\mathrm{C}(\mathrm{PKC})$ is not involved (Tempia et al., 1998; Canepari et al., 2001). The ionic mechanism of the PF-mGlu ${ }_{1}$-EPSC is associated with a relevant sodium influx, which has been studied by optical methods (Knöpfel et al., 2000). As a result of several pioneering studies, hyperpolarization-activated cation channels (Canepari et al., 2001), purinergic receptors (Canepari et al., 2001), $\mathrm{Na}^{+} / \mathrm{Ca}^{2+}$-exchangers (Hirono et al., 1998) and voltage-gated $\mathrm{Ca}^{2+}$ channels (Tempia et al., 2001) have been excluded as molecular candidates responsible for the generation of the $\mathrm{mGlu}_{1}$-induced inward current in PCs. A few years later, it was shown that the $\mathrm{mGlu}_{1}$-induced current is in part mediated by a member of the class of canonical transient receptor potential (TRPC) channels (Kim et al., 2003), subsequently identified as TRPC3 (Hartmann et al., 2008). Recently, it has been proposed that activation of delta-2 glutamate (GluD2) receptors can also contribute to the PF-mGlu ${ }_{1}$-EPSC (Ady et al., 2014). GluD2 is an ion channel selectively permeable to the monovalent cations, unlike the TRPC3 channel, which has a non-selective permeability to $\mathrm{Na}^{+}$and $\mathrm{Ca}^{2+}$, GluD2 is not gated by glutamate, so that for a long time it had been considered an orphan receptor, belonging to the glutamate receptors family merely on the basis of sequence similarity with the other members of this group. Since the mechanism of GluD2 gating upon glutamate binding to $\mathrm{mGlu}_{1}$ receptors is not known, further studies are necessary to confirm this finding.

Although the PF-mGlu ${ }_{1}$-EPSC does not require release of $\mathrm{Ca}^{2+}$ from internal stores of the endoplasmic reticulum (Tempia et al., 2001), it is strongly modulated by extracellular (Tempia et al., 1998, 2001; Tabata et al., 2002) and by intradendritic $\mathrm{Ca}^{2+}$ (Batchelor and Garthwaite, 1997; Tempia et al., 1997). Because of its sensitivity to intracellular $\mathrm{Ca}^{2+}, \mathrm{PF}-\mathrm{mGlu}_{1}$ EPSC acts as coincidence detector. In fact, a train of PF action potentials, combined with an elevation of intradendritic $\mathrm{Ca}^{2+}$, causes a marked potentiation of the PF-mGlu ${ }_{1}$-EPSC (Batchelor and Garthwaite, 1997; Tempia et al., 1997; Dzubay and Otis, 2002). It should be pointed out that PCs possess several mechanisms for the control of intradendritic $\mathrm{Ca}^{2+}$. The first route of $\mathrm{Ca}^{2+}$ entry into $\mathrm{PC}$ dendrites is constituted by voltage-dependent $\mathrm{Ca}^{2+}$ channels. Thus, all mechanisms that depolarize PC dendrites enough to reach the threshold for $\mathrm{Ca}^{2+}$ channel gating can generate intradendritic $\mathrm{Ca}^{2+}$ signals. In fact, a strong activation of PFs can evoke a localized dendritic $\mathrm{Ca}^{2+}$ elevation (Eilers et al., 1995; Rancz and Häusser, 2006). However, the largest $\mathrm{Ca}^{2+}$ signals of PC dendrites are caused by the massive depolarization due to the activation of the CF-PC synapse, but in this case, the signal is spread throughout the dendritic tree (Konnerth et al., 1992; Miyakawa et al., 1992). Moreover, the coincidence of PF and CF activity has an additive effect leading to even larger elevations of intradendritic $\mathrm{Ca}^{2+}$ localized to the dendritic spines receiving both signals (Wang et al., 2000). 


\section{PLASTICITY OF THE PARALLEL FIBER-PURKINJE CELL SYNAPSE}

Long-term potentiation (LTP) and long-term depression (LTD) of the PF-PC synapses refer to long-lasting increase or decrease, respectively, of synaptic transmission. In the last decade, many studies have revealed that both forms of plasticity can occur in vivo and likely mediate some forms of learning, although the relationship between any one form of synaptic plasticity and a particular type of memory is still under debate (D'Angelo et al., 2016). These studies have also uncovered a wide range of induction mechanisms of synaptic plasticity, which converge not only on the presynaptic terminal where an enduring modification in the neurotransmitter release process takes place but also on the postsynaptic change in responsiveness to the neurotransmitter. It is now clear that presynaptic forms of LTP/LTD can co-exist with classical forms of postsynaptic plasticity at the PF-PC synapses but their induction and expression mechanisms appear to be almost completely distinct (see below). Interestingly, synaptic plasticity at PF-PC synapse can also be associated with persistent changes in intrinsic excitability of the same neurons, due to use-dependent modulation of voltage-gated ion channels (Mapelli et al., 2015). The combination of changes in synaptic strength and in intrinsic excitation can optimize information transfer within the cerebellar network and may thus contribute to the formation of the memory trace.

\section{Long-Term Depression (LTD)}

LTD at the PF-PC synapse is the best characterized form of synaptic plasticity in the cerebellum since it is believed to underlie several forms of motor learning, including the adaptation of the vestibulo-ocular reflex (VOR), associative eyeblink conditioning, and limb load adjustment (Ito, 1982, 1989; Krupa and Thompson, 1997). Indeed, an important feature of cerebellar LTD is the property of associativity: the long-lasting depression of $\mathrm{PF}$ responses results from the coincident activation of CF and PF inputs to a PC. LTD was originally described in vivo by Ito et al. (1982) in decerebrated rabbits. In this study, they demonstrated that stimulation of the vestibular nerve, which conveys mossy fibers to the flocculus, conjunctively with the stimulation of the inferior olive, the sole source of $\mathrm{CFs}$, induced a long-lasting depression of the PC responses to vestibular nerve stimulation. Afterward, studies of in vitro preparations (i.e., cerebellar slices and cultures) have provided further insight into the cellular and molecular mechanisms of LTD (Ito, 2002). These studies indicate that PF-LTD requires the $\mathrm{Ca}^{2+}$ influx through $\mathrm{P} / \mathrm{Q}$ voltage-gated channels, triggered by the CF-evoked depolarization, together with the release of glutamate by PFs, which acts upon both $\mathrm{mGlu}_{1}$ metabotropic receptors and AMPA receptors (Figure 1A). As reported above, stimulation of the $\mathrm{mGlu}_{1}$ receptor promotes, via G-protein $\left(\mathrm{G}_{\mathrm{q} / 11}\right)$, DAG production and $\mathrm{Ca}^{2+}$ release from the endoplasmic reticulum (Aiba et al., 1994; Conquet et al., 1994; Matsumoto et al., 1996; Ichise et al., 2000; Hirono et al., 2001; Miyata et al., 2001; Hartmann et al., 2004; Kano et al., 2008). The PF-induced release of $\mathrm{Ca}^{2+}$ together with the $\mathrm{Ca}^{2+}$ entry evoked by CF stimulation determines a significant increase of $\mathrm{Ca}^{2+}$ concentration particularly at the level of spines and shafts of PC dendrites (Miyakawa et al., 1992; Eilers et al., 1995). DAG and $\mathrm{Ca}^{2+}$ act synergistically to activate PKC, which in turn activates a series of kinases, including Raf, MEK and ERK1/ERK2 (Tanaka and Augustine, 2008). Among the different PKC isoforms expressed in PCs, PKC $\alpha$ is critically required for LTD induction (Leitges et al., 2004). Indeed, cerebellar LTD is absent in PCs derived from PKC $\alpha$ null mice and is rescued by transfection with an expression plasmid encoding PKC $\alpha$ but not other PKC isoforms (Leitges et al., 2004). Activated PKC induces the phosphorylation of AMPA receptors at serin- 880 of the GluA2 terminus, which results in the elimination of the receptor from the dendritic spines via clathrin-mediated endocytosis (Wang and Linden, 2000). The reduction in the number of postsynaptic AMPA receptors represents the key change for LTD expression since it is responsible for the reduced responsiveness to glutamate and therefore for the decreased transmission at the PF-PC synapse. It is now clear that the endocytic removal of postsynaptic AMPA receptors is a complex phenomenon regulated by the interaction of GluA2 not only with PKC but also with glutamate receptor-interacting proteins (GRIP1 and GRIP2/ABP) and the PDZ domain-containing protein PICK1 (protein interacting with $C$ kinase 1). In particular, it has been demonstrated that GluA2 binds GRIP1 and GRIP2 in the dephospho-Ser880 state; however, when GluA2 Ser-880 is phosphorylated by PKC, the affinity of GRIP1/2 for GluA2 is disrupted and this allows the binding of the receptor to PICK1 (Hirai, 2001). PICK1 is indeed considered a key regulator of AMPA receptor traffic since it is directly involved in the removal of AMPA receptors from the synaptic plasma membrane (Hanley, 2008). Recently, it has been found that the targeting of PKC $\alpha$ to the synapses is also regulated by a diacylglycerol kinase $\zeta$ (DGK $\zeta)$, that can interact with $\mathrm{PKC} \alpha$ and as well as with postsynaptic density protein 95 (PSD-95; Lee et al., 2015). DGK $\zeta$ has the ability to metabolize DAG thus reducing the PKC $\alpha$ activity to the basal level. Following LTD induction, the activated PKC $\alpha$ phosphorylates and releases DGK $\zeta$ so that PKC $\alpha$ can interact with PICK1 to enhance AMPA receptors internalization. By recruiting Raf kinase, PKC can also induce the sequential activation of MEK, ERK1/2 and phospholipase $\mathrm{A}_{2}$, resulting in the production of arachidonic acid and subsequent activation of PKC. The MAPK-PKC positive feedback loop is likely responsible for the sustained PKC activation and the maintenance of LTD (Yamamoto et al., 2012).

\section{Presynaptically Expressed LTP}

In addition to LTD, PF-PC synapses can undergo both preand postsynaptically expressed types of LTP (Figures 1B,C). The presynaptically expressed LTP is induced by brief PF stimulations at the frequency of $4-8 \mathrm{~Hz}$. The leading event is the increase of $\mathrm{Ca}^{2+}$ influx within PF terminals that activates a $\mathrm{Ca}^{2+} /$ calmodulin-dependent adenylyl cyclase, resulting in enhanced presynaptic cAMP levels and protein kinase A (PKA) activation (Salin et al., 1996; Chen and Regehr, 1997; Storm et al., 1998; Jacoby et al., 2001). PKA then phosphorylates the 

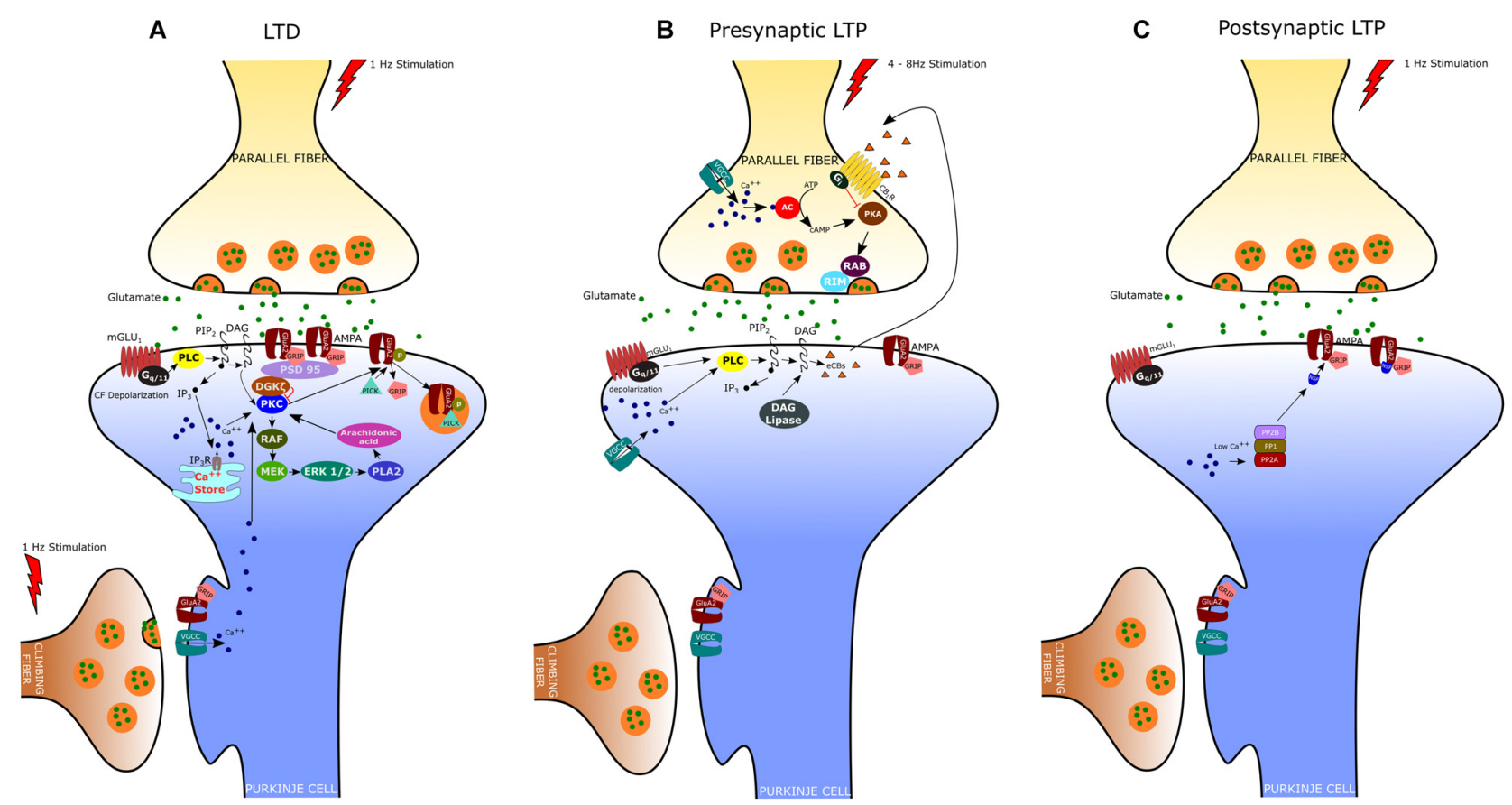

FIGURE 1 | Expression mechanisms of long-term depression (LTD), presynaptic Long-term potentiation (LTP) and postsynaptic LTP. (A) LTD is induced by conjunctive stimulation of parallel and climbing fibers (CF) and requires postsynaptic $\mathrm{Ca}^{2+}$ elevation (see text). (B) Presynaptic LTP can be induced by brief PF stimulations at $4-8 \mathrm{~Hz}$. A retrograde signaling mechanism mediated by cannabinoids regulates presynaptic LTP. The release of endogenous cannabinoids (eCBs) from the postsynaptic membrane is evoked by high-frequency bursts of parallel fiber activity and depends on the activation of postsynaptic mGlu 1 receptors. eCBs act retrogradely onto presynaptic cannabinoid 1 receptors $\left(C B_{1} R\right)$, causing suppression of transmitter release. (C) Postsynaptic LTP can be induced by parallel fiber stimulation at $1 \mathrm{~Hz}$ and requires low levels of $\mathrm{Ca}^{2+}$ in the $\mathrm{PC}$

vesicle-release related proteins, RIM1 $\alpha$ and Rab3, thus increasing glutamate release from PFs (Kaeser et al., 2008). Although most of the presynaptic $\mathrm{Ca}^{2+}$ enters $\mathrm{PFs}$ through $\mathrm{N}$-type and P/Q-type $\mathrm{Ca}^{2+}$ channels, PF-LTP can still occur when both of these channel types are blocked and the global $\mathrm{Ca}^{2+}$ levels are largely reduced by 50\% (Myoga and Regehr, 2011). On the other hand, blocking R-type $\mathrm{Ca}^{2+}$ channels disrupts PF-LTP, despite these channels play a minor role in basal transmission and contribute modestly to overall $\mathrm{Ca}^{2+}$ entry. Presynaptic LTP appears to be finely regulated by endocannabinoids (eCB), which are released by PCs following PF stimulation (Maejima et al., 2001, 2005; Brown et al., 2003). Activation of $\mathrm{CB}_{1}$ receptors on $\mathrm{PF}$ terminals inhibits $\mathrm{AC}$ and $\mathrm{PKA}$ activity, thus preventing LTP induction. Interestingly, the coactivation of CF can enhance $\mathrm{eCB}$ retrograde inhibition of $\mathrm{PF}$ transmission thus promoting PF-LTD while suppressing PF-LTP (van Beugen et al., 2006).

\section{Postsynaptically Expressed LTP}

The postsynaptically expressed LTP is evoked by PF stimulation at low frequency (typically $1 \mathrm{~Hz}$ ) that triggers the GluA2-containing AMPA receptors insertion in the spine membrane. The GluA2 subunit insertion at synaptic sites involves N-ethylmaleimide-sensitive factor (NSF), an essential component of SNARE-mediated fusion machinery, which binds GluA2 and reduces the receptor internalization by PICK1
(Anggono and Huganir, 2012). In contrast, during LTD, the elevated postsynaptic $\left[\mathrm{Ca}^{2+}\right]$ inhibits NSF-GluA2 interaction, thus promoting GluA2-PICK1 binding and synaptic removal of GluA2-containing AMPA receptors. Unlike LTD, the induction of postsynaptic LTP depends on lower $\mathrm{Ca}^{2+}$ transients and requires the activation of protein phosphatases PP1, PP2A and PP2B (Belmeguenai and Hansel, 2005). These phosphatases enhance GluA2 binding to GRIP, which in turn stabilizes the AMPA receptors to the membrane. Indeed, mutant mice, in which the PP2B (or calcineurin) was deleted only in cerebellar PCs, show deficit in postsynaptic PF-PC LTP and motor learning, whereas LTD induction was unaffected (Schonewille et al., 2010).

\section{Parallel Fiber-Purkinje Cell Plasticity in Motor Learning}

The observation of concomitant impaired LTP and motor learning, with no alteration of LTD, challenged the common view that cerebellar LTD alone underlies motor learning. Indeed, cerebellar motor learning during eyeblink conditioning and adaptation of the VOR appears to be completely normal in mutants in which LTD induction was impaired by inactivation of AMPA receptor internalization (Schonewille et al., 2011). This suggests that learning may result from the interaction of several forms of synaptic plasticity and not just from classical 
LTD alone. Indeed, it is now clear that different forms of plasticity take place in the granular layer, in the molecular layer and DCN involving both excitatory and inhibitory synaptic transmission (Gao et al., 2012; D’Angelo et al., 2016). These forms of synaptic plasticity are believed to operate in conjunction with long-lasting modifications in neuronal excitability during memory formation in the cerebellum (Schreurs et al., 1998; Belmeguenai et al., 2010; Grasselli et al., 2016). Indeed, Purkinje cell recordings from cerebellar slices of rabbits that had acquired delay eyelid conditioning revealed an increased PC membrane excitability that lasted for 30 days after training.

But what is then the role of CFs? The principal hypothesis is that the complex spike discharge of PCs encodes motor error signals and serves as a teaching signal that drives motor adaptation. This means that LTD should be driven by error-related signals carried by CFs whereas LTP should occur when such error signals are absent, without CF supervision (Sakurai, 1987). A corollary of this hypothesis is that the CFs may regulate PC activity under certain conditions, such as when attention is enhanced or errors in motor execution become large, as suggested Kimpo et al. (2014). In their study, monkeys sat in a rotating chair (to provide vestibular stimuli), and were trained to track a visual object with their eyes. They found that when the visual stimulus was moved in the opposite direction from the vestibular stimulus so that a bigger reflexive eye movement was required to stabilize the image (VOR-increase training), the activation of the CFs in response to the error led to a change in the response of the PCs. However, when the visual stimulus moved together with the head and a smaller reflexive eye movement was needed (VOR-decrease training), the error signals carried by CFs did not alter the PC firing rate. Interestingly, the optogenetic activation of CFs, mimicking the visual error signals provided by retinal slip, was able to induce VOR-increase but not VOR-decrease learning. These results indicate that the CF activity and the plasticity of the PC responses are not so correlated during VOR-decrease training, as they are during VOR-increase learning. Thus, although both motor learning paradigms elicited error signals in the CFs, PCs could regulate the CF-triggered plasticity.

Moreover, there is growing evidence that long-term plastic changes can occur in the cerebellar cortical network in the absence of the intervention of CFs. For example, Ramakrishnan et al. (2016) have recently demonstrated that theta burst tactile stimulation (a burst of 80 air puffs delivered at $4 \mathrm{~Hz}$ ) mimicking natural stimulation patterns can induce a long-lasting potentiation of PC discharge and long-lasting decrease of molecular layer interneurons firing in the absence of complex spike changes. Interestingly, there are also indications that memory of fear is accompanied by LTP at PF-PC synapses, which is consistent with the view that Hebbian learning occurs in the cerebellar cortex during fear conditioning (Sacchetti et al., 2004; Zhu et al., 2007). This fear conditioning-induced potentiation is postsynaptically expressed and displays some properties of LTP elicited in vitro by repetitive stimulation of PFs.

\section{MODULATION OF THE PARALLEL FIBER-PURKINJE CELL SYNAPSE BY NEUROTRANSMITTERS}

The cerebellar cortex receives projections from multiple neuromodulatory neurons releasing acetylcholine, norepinephrine, and serotonin (Schweighofer et al., 2004). The cell bodies of these neuromodulatory neurons are mainly grouped in specific nuclei in the brainstem, and through their widespread projections, they distribute to all parts of the cerebellar circuitry, i.e., cerebellar cortex and DCN. Because of this widespread projection, the neuromodulatory system can have profound effects on excitability and synaptic plasticity of target neurons (Ito and Schuman, 2008). Indeed, electrophysiological and behavioral studies have demonstrated that neuromodulation is implicated in cerebellar processing as well as cerebellar-dependent learning and memory.

\section{Serotonin}

The cerebellum receives a dense innervation by serotonergic fibers, which represent the third largest population of afferent fibers extending into this brain region, after mossy and CFs. The serotonin inputs to the cerebellum originate mainly in the medullary and pontine reticular formation and distribute to both cerebellar cortex and nuclei (Chan-Palay, 1975; Bishop and Ho, 1985). Anatomical and pharmacological studies indicate that the cerebellar cortex expresses multiple subtypes of 5-hydroxytriptamine receptors (5-HTRs). In particular, there is clear evidence that PCs express the $5-\mathrm{HT}_{1}, 5-\mathrm{HT}_{2}, 5-\mathrm{HT}_{5}$ and $5-\mathrm{HT}_{7}$ subtypes whereas $5-\mathrm{HT}_{3} \mathrm{Rs}$ and $5-\mathrm{HT}_{6} \mathrm{Rs}$ are localized on granule cells (Pazos and Palacios, 1985; Geurts et al., 2002; Li et al., 2004). Expression of $5-\mathrm{HT}_{5 \mathrm{~A}} \mathrm{R}$ has also been found on Golgi cells and molecular layer interneurons (Geurts et al., 2002; Oostland et al., 2014). Given the widespread distribution of serotonergic innervation and the richness of signals evoked by different 5 -HTR subtypes, it is not surprising that 5 -HT has the potential to modulate both excitatory and inhibitory synaptic signals throughout the cerebellar network. Indeed, it has been shown that activation of $5-\mathrm{HT}_{1} \mathrm{Rs}$ determines a general suppression of cerebellar cortex activity by reducing the release of the excitatory transmitter glutamate from PFs to PCs (Maura et al., 1986) and by increasing inhibitory synaptic transmission onto PCs (Mitoma et al., 1994; Mitoma and Konishi, 1999).

By using patch-clamp recordings in cerebellar slices of adult mice, Lippiello et al. (2016) have recently demonstrated that $5-\mathrm{HT}_{7} \mathrm{Rs}$ are critically implicated in synaptic plasticity of the PF-PC synapse, thus providing a novel cellular and molecular basis for the action of 5-HT at cerebellar level. In particular, they found that $5-\mathrm{HT}_{7} \mathrm{R}$ activation by a selective agonist causes LTD of the PF-PC synapse via a postsynaptic mechanism that involves the PKC-MAPK signaling pathway (Figure 2A). As previously described, MAPK activation may trigger a positive feedback, via phospholipase $A_{2}$, which is responsible for a sustained activation of $\mathrm{PKC}$ and consequent internalization of AMPA receptors. In addition, they showed that treatment with a $5-\mathrm{HT}_{7} \mathrm{R}$ antagonist reduced the expression 

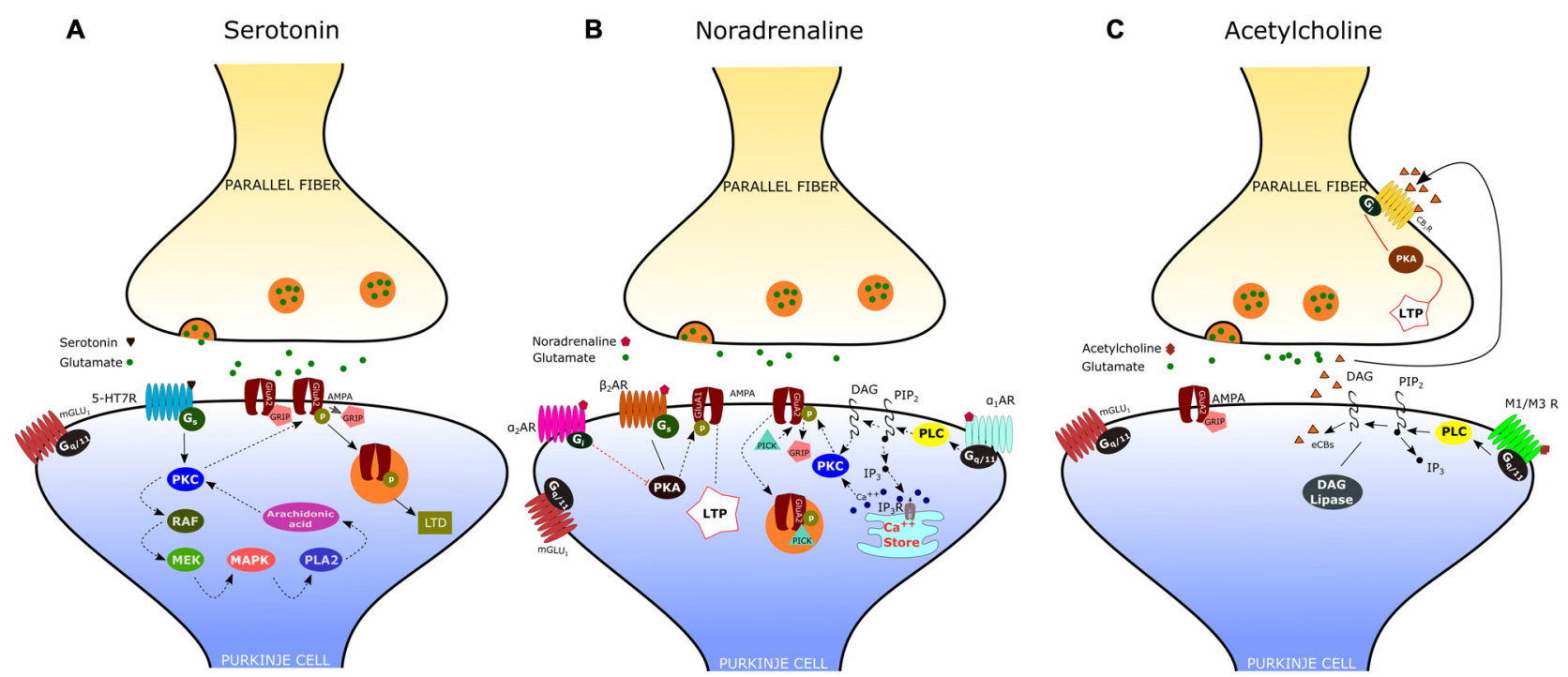

FIGURE 2 | Neuromodulation of the parallel fiber-Purkinje cell (PF-PC) synapse. (A) Activation of the serotonin receptor $5-\mathrm{HT}_{7} \mathrm{R}$ elicits the depression of the PF-PC synapse via a postsynaptic mechanism that involves the protein kinase C (PKC)-MAPK signaling pathway (see text). (B) $\alpha$-adrenergic receptors $\left(\alpha_{1}\right.$-ARs) exert an inhibitory effect on PF-PC synaptic transmission via $G_{q / 11}$ and phospholipase $C$ (PLC). $\alpha_{2}$-ARs are known to inhibit adenylyl cyclase, via $G_{i}$-proteins, leading to a decrease of CAMP concentration and protein kinase A (PKA). $\beta$-ARs activation facilitates the PF-PC synaptic transmission via the CAMP-PKA signaling pathway. (C) Acetylcholine induces a transient depression of PF-excitatory post-synaptic currents (EPSCs) via $M_{1} / M_{3}$ postsynaptic muscarinic receptors, which are coupled to $G_{c}$ and linked to the cannabinoid signaling pathway.

of postsynaptic PF-LTD, produced by pairing PF stimulation with PC depolarization; on the other hand, application of a $5-\mathrm{HT}_{7} \mathrm{R}$ agonist impaired postsynaptic LTP induced by $1 \mathrm{~Hz}$ stimulation of PFs. These results suggest that $5-\mathrm{HT}_{7} \mathrm{R}$ exerts a fine regulation of bidirectional synaptic plasticity by favoring the emergence of LTD vs. LTP at PF-PC synapses. This type of synaptic control may enable the serotonergic pathways to prevent the simultaneous occurrence of conflicting forms of plasticity at PF-PC, such as potentiation of synaptic transmission under conditions that promote postsynaptic LTD.

The involvement of serotonin 5-HT in motor learning has been observed in several cerebellar-dependent paradigms. For example, depletion of brain 5-HT has been shown to impair the horizontal VOR adaptation in rabbits (Miyashita and Watanabe, 1984). In addition, application of a 5-HT receptor (5-HTR) antagonist, ritanserin, to the cerebellar vermis before training, impaired the formation of long-term memory of conditioned freezing and extinction of the defensive component of the acoustic startle reaction (Storozheva and Proshin, 2011). Furthermore, chronic treatment with buspirone, a 5-HT1AR partial agonist, improves the motor coordination deficits in Lurcher mouse, a model of cerebellar neurodegeneration (Le Marec et al., 2001). Serotonergic modulation of the cerebellum has been also a subject of clinical interest since the discovery that long-term administration of L-5-hydroxytryptophan, a precursor of 5-HT, improves the dysfunctions associated with cerebellar disorders in patients with inherited or acquired ataxia (Trouillas et al., 1988, 1995). Furthermore, there is evidence that neurodevelopmental disorders such as autism and schizophrenia are associated with a change in 5-HTR expression in the cerebellum (Slater et al., 1998; Eastwood et al., 2001).

\section{Noradrenaline}

The noradrenergic innervation of the cerebellum originates from the locus coeruleus and distributes to all parts of the cerebellar cortex and DCN (Olson and Fuxe, 1971; Abbott and Sotelo, 2000). Studies using lesions and pharmacological approaches combined with behavioral analysis have provided a direct evidence that the noradrenergic locus coeruleus system is implicated in a wide variety of brain processes, including attention, arousal, decision making and memory (AstonJones et al., 1999; Clayton et al., 2004). The demonstration that the cerebellar cortex receives a widespread projection from the locus coeruleus has led researchers to hypothesize that the noradrenergic system may also be involved in the modulation of cerebellar functions and motor learning. To test this hypothesis, van Neerven et al. (1990) examined the effect of the noradrenergic system on the adaptive changes of the VOR in rabbits. They found that the injection of a $\beta$-adrenergic agonist, isoproterenol, into the flocculus enhanced the adaptive potentiation of VOR particularly in darkness; whereas the application of a $\beta$-antagonist, sotalol, significantly reduced the adaptation of the VOR in the light and darkness. Further studies in rabbit and rat have demonstrated that blockade of $\beta$-adrenergic receptors ( $\beta$-ARs) through systemic administration of propranolol impaired the acquisition of the eyeblink conditioning (Gould, 1998; Cartford et al., 2002). Abnormal levels of noradrenaline (norepinephrine: NE) have 
been noted in the cerebella of patients with olivocerebellar atrophy, Parkinson's and Alzheimer's diseases (Kish et al., 1984a,b; Shimohama et al., 1986).

In situ hybridization studies indicate that the cerebellar cortex expresses mRNA encoding all subtypes of $\alpha_{1}$-AR $\left(\alpha_{1 A}, \alpha_{1 B}\right.$, $\left.\alpha_{1 D}\right)$ and $\alpha_{2}$-AR $\left(\alpha_{2 A}, \alpha_{2 B}, \alpha_{2 C}\right.$; Schambra et al., 2005). These results are confirmed by immunostainings analyses showing a strong expression of $\alpha_{1 A}-A R$ as well as $\alpha_{2 A}$ - and $\alpha_{2 B}-A R$ in both molecular layer interneurons and PCs (Papay et al., 2004, 2006; Hirono et al., 2008). High-level expression of $\beta_{2}$-AR has been also observed in PC bodies and molecular layer (Lippiello et al., 2015).

According to electrophysiological studies, iontophoretically applied NE or activation of the locus coeruleus induces depression of spontaneous discharges in PCs (Hoffer et al., 1971; Siggins et al., 1971). Such effect is associated with the potentiation of inhibitory GABAergic transmission at basket cell-PC synapses, mediated by presynaptic $\beta_{2}$-ARs (Mitoma and Konishi, 1999; Saitow and Konishi, 2000). Interestingly, NE exerts also an inhibitory effect on the CF-PC synapse, acting presynaptically (on $\alpha_{2}$-ARs) to decrease glutamate release from CFs (Carey and Regehr, 2009). Concerning the noradrenergic effect on the PF-PC synapse, early reports have shown an inhibitory action of NA, mediated by $\alpha_{2}$-ARs, on the field potential evoked by PF stimulation (Mitoma and Konishi, 1999). Recent evidence indicates that noradrenaline functions as an endogenous ligand for both $\alpha_{1}$ - and $\alpha_{2}$-ARs to produce synaptic depression between PFs and PCs, through a postsynaptic mechanism. (Figure 2B; Lippiello et al., 2015). This result is consistent with the immunochemical localization of both $\alpha_{1}$ - and $\alpha_{2}$-ARs at the Purkinje cell dendrites (Papay et al., 2004, 2006; Hirono et al., 2008). The inhibitory effect $\alpha_{1}$-ARs on PF-PC synaptic transmission is likely related to the sequential activation of $\mathrm{G}_{\mathrm{q} / 11}$ and PLC which may induce DAG production and release of $\mathrm{Ca}^{2+}$ from intracellular stores. This may result in the activation of PKC and eventually phosphorylation of GluA2 and internalization of AMPA receptors (Herold et al., 2005). $\alpha_{2}$-ARs are known to inhibit adenylyl cyclase, via $G_{i}$ proteins, leading to a decrease in cAMP concentration and PKA activity. A decrease in PKA activity determines the dephosphorylation of GluA1, which is considered a signal for internalization and synaptic depression (Yi et al., 2013). On the other hand, stimulation of the $\beta$-AR by isoproterenol determines a significant increase of PF-EPSCs (Lippiello et al., 2015). This short-term potentiation is postsynaptically expressed, requires PKA, and is mimicked by the $\beta_{2}$-AR agonist clenbuterol. Interestingly, activation of $\beta$-ARs facilitates PF-PC synaptic plasticity by enhancing the ability of low-threshold stimuli to induce postsynaptic LTP. The mechanism by which $\beta$-ARs facilitate synaptic transmission may involve the cAMP-PKA signaling pathway. Indeed it has been demonstrated that PKA can phosphorylate GluA1 on S845 thus promoting AMPA receptor insertion into synapses (Joiner et al., 2010). Such bidirectional regulation of PF-PC synaptic transmission by $\mathrm{NE}$ with facilitation via $\beta_{2}$-ARs and inhibition via $\alpha_{1}$-and $\alpha_{2}$-ARs may allow the noradrenergic inputs to finely regulate the signals arriving at PCs at particular arousal states or during learning.

\section{Acetylcholine}

The presence of cholinergic innervation in the cerebellum has been demonstrated by earlier immunocytochemical studies using antibodies against choline acetyltransferase (ChAT). Such analysis combined to retrograde tracing has revealed a significant amount of ChAT-positive mossy fibers in the flocculo-nodular lobe, originating mainly from the vestibular nuclei, and a moderate number of ChAT-immunoreactive fibers in the DCN (Barmack et al., 1992; Jaarsma et al., 1997). Autoradiographic and immunohistochemical analysis have later provided evidence that the cerebellum expresses both muscarinic and nicotinic cholinergic receptors. Muscarinic receptors are mainly $\mathrm{M}_{2}$-type and are localized throughout the whole cerebellar cortex, particularly in the molecular layer of nodulus and ventral uvula, and in the cerebellar nuclei. On the other hand, the cerebellum expresses several subtypes of nicotinic acetylcholine receptors (nAChRs), with a predominance of the homomeric $\alpha_{7}$-nAChRs and the heteromeric nAChRs composed of $\alpha_{3}$ or $\alpha_{4}$ subunits in pairwise combination with either $\beta_{2}$ or $\beta_{3}$ subunits (Turner and Kellar, 2005). A specific nAChR expression has been observed in interneurons, granule cells and mossy fibers. These results are consistent with electrophysiological studies showing an increase of GABA release from Golgi cells and basket/stellate interneurons following activation of nAChRs (Rossi et al., 2003). Furthermore, it has been demonstrated that nicotine increases mossy fiber-granule cell synaptic transmission by acting on $\alpha_{7}$-nAChRs located at preand postsynaptic sites. On the other hand, Rinaldo and Hansel (2013) have recently demonstrated that muscarinic acetylcholine receptors ( $\mathrm{mAChRs}$ ) activation by a selective agonist induces a transient depression of PF-AMPA-EPSCs via a presynaptic effect mediated by $\mathrm{M}_{3}$ receptors. Interestingly, mAChR activation has also a suppressive effect on presynaptic LTP induction at $\mathrm{PF}-\mathrm{PC}$ synapses via retrograde eCB signaling. According to their results, the $\mathrm{eCB}$ synthesis and release occurs at the postsynaptic site and is triggered by $G_{\mathrm{q}}$-coupled $\mathrm{M}_{1} / \mathrm{M}_{3}$ receptors expressed on PCs (Figure 2C). The effect of eCB is likely mediated by cannabinoid 1 receptors $\left(\mathrm{CB}_{1} \mathrm{Rs}\right)$, located in presynaptic terminals and consists in a reduced release of neurotransmitter through a $\mathrm{G}_{\mathrm{i} / \mathrm{o}}$-coupled pathway. Therefore, by activating multiple cholinergic receptor subtypes on different cellular targets, acetylcholine has the potential to modulate the cerebellar information processing within the cerebellar cortex.

Evidence for a role of cholinergic signaling in cerebellar motor learning has come from behavioral studies showing that the injections of muscarinic agonists into the vestibulocerebellum influenced the gains of optokinetic and vestibuloocular reflexes in the rabbit and the VOR gain in the decerebrate cat (Andre et al., 1992; Tan et al., 1993; van der Steen and Tan, 1997). The effect of nicotine has also been studied in human subjects scanned by functional magnetic resonance while performing an auditory-paced finger tapping task (Wylie et al., 2013). The task consisted in pressing a button with their right hand in response to an auditory cue at a constant rate of 1,2 or $4 \mathrm{~Hz}$. When compared to placebo treatment, subjects that received nicotine treatment showed an increased tapping rate, as a consequence of increased 
coordination, associated with an increased activity in the vermal area of the anterior cerebellum during the task.

nAChRs are also involved in developmental plasticity in the chick cerebellum and neurodevelopmental disorders such as autism (Kaneko et al., 1998). Indeed, developmental synaptogenic events are often accompanied by an increase in $\mathrm{PC} \alpha_{7} \mathrm{nAChR}$ immunoreactivity. On the other hand, an abnormal expression of $\mathrm{nAChR} \alpha_{4}$ and $\alpha_{7}$ has been observed in the cerebellar cortex of autistic subjects compared to normal individuals (Lee et al., 2002).

\section{ALTERATIONS OF THE PARALLEL FIBER-PURKINJE CELL SYNAPSE IN NEUROLOGIC AND PSYCHIATRIC DISEASES}

\section{Spino-Cerebellar Ataxias}

The PF-PC synapse is involved in several disorders with altered cerebellar function. Regarding neurologic diseases, most studies have been focused on spino-cerebellar ataxias (SCAs), hereditary forms of cerebellar disorder with an autosomic dominant transmission pattern and with a variable involvement of extra-cerebellar structures. At present, the mutations responsible for more than 40 distinct types of SCAs have been described (Durr, 2010), but the cause of a large fraction of SCAs (20-60\%, depending on the geographical origin) is still unknown (Durr, 2010). The SCAs 1-3, 6-7, 17 and dentatorubral-pallidoluysian atrophy (DRPLA) are due to the expansion of CAG triplets coding for polyglutamine. SCA10, SCA12 and SCA31 are due to the expansion of non-coding regions of genes. The remaining SCAs are due to conventional mutations. The mechanisms of the SCAs affecting the PF-PC synapse are summarized in Figure 3.

\section{SCA1}

In several types of SCA the expression and/or function of $\mathrm{mGlu}_{1}$ receptors is altered in PCs. In SCA1, a polyglutamine repeat expansion of the protein ataxin 1 causes a dysregulation in the expression of several genes, including members of the PC $\mathrm{mGlu}_{1}$ receptor signaling pathway (Serra et al., 2004). The protein expression levels of the $\mathrm{mGlu}_{1}$ receptor are reduced in the dendritic tree of PCs in SCA1 transgenic mice ( $\mathrm{Zu}$ et al., 2004). In this model, silencing the SCA1 transgene restored both $\mathrm{mGlu}_{1}$ receptor expression and motor function, suggesting a causative role of this signaling pathway in ataxic symptoms ( $\mathrm{Zu}$ et al., 2004). The reduction in the expression of $\mathrm{mGlu}_{1}$ receptor mRNA and protein levels in a SCA1-model mouse with severe ataxia was confirmed by Notartomaso et al. (2013). Treatment of these mice with a positive allosteric modulator of the $\mathrm{mGlu}_{1}$ receptor caused a long-lasting improvement of motor performance (Notartomaso et al., 2013). However, in these studies, the $\mathrm{mGlu}_{1}$-EPSC was not assessed, so that the role of $\mathrm{mGlu}_{1}$-mediated synaptic signaling at the PF-PC synapse remains uncertain. A recent report showed that, in SCA1-model mice with moderate ataxia, the $\mathrm{mGlu}_{1}$-EPSC is of similar amplitude as in controls, but with a prolonged time course (Power et al., 2016). In this case, the administration of a negative

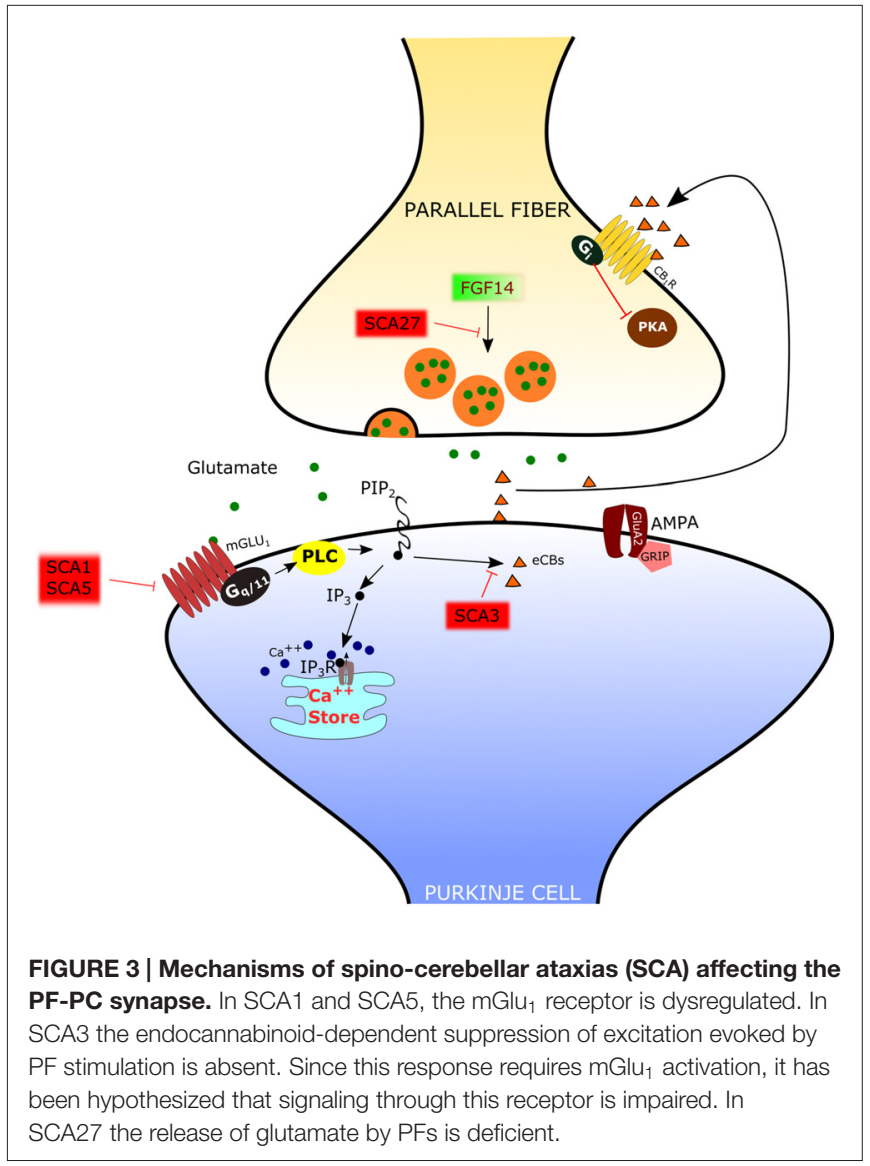

allosteric modulator of $\mathrm{mGlu}_{1}$ receptors shortened the $\mathrm{mGlu}_{1}$ EPSC to control levels and rescued the ataxic symptoms (Power et al., 2016). More studies are still necessary to understand the role of $\mathrm{mGlu}_{1}$ receptor signaling in different murine models of SCA1, in order to disclose how it affects the progression of symptoms so that an appropriate therapeutic approach can be used depending on the hyper- or hypo-activity of the $\mathrm{mGlu}_{1}$ receptor pathway.

\section{SCA3}

SCA3 is also due to polyglutamine expansion. In SCA3-model mice, there is a complete loss of the synaptically evoked suppression of excitation, which is endocannabinoid dependent (Konno et al., 2014). Synaptically evoked suppression of excitation is obtained by a brief burst of PF stimulation and requires the intradendritic $\mathrm{Ca}^{2+}$ signal, meditated by $\mathrm{mGlu}_{1}$ receptor activation, and dendrite depolarization (Maejima et al., 2001, 2005; Brown et al., 2003). For this reason, the absence of the synaptically evoked suppression of excitation is an indirect evidence that the $\mathrm{mGlu}_{1}$ receptor pathway is impaired in the SCA3 mouse model (Konno et al., 2014).

\section{SCA5}

SCA5 is due to mutations of beta-III spectrin, which is a scaffold protein interacting with the $\mathrm{mGlu}_{1}$ receptor (Armbrust et al., 2014). In SCA5-model mice, the mGlu $_{1}$ receptor is decreased 
in the dendritic spines of PCs, $\mathrm{mGlu}_{1}$-mediated $\mathrm{Ca}^{2+}$ responses are impaired and $\mathrm{mGlu}_{1}$-dependent LTP is deficient (Armbrust et al., 2014).

\section{SCA27}

SCA27 is due to loss-of-function mutations of the FGF14 gene (van Swieten et al., 2003). SCA27 patients display ataxia, tremor, dyskinesia, intellectual disability and deficits in memory and executive functioning (Brusse et al., 2006). FGF14 codes for a protein, FGF14, which belongs to the family of fibroblast growth factors (FGFs). However, in contrast to most other members of this family, FGF14 is not secreted but it is retained intracellularly and interacts with voltage-dependent sodium $\left(\mathrm{Na}_{V}\right)$ channels to modulate their function (Goldfarb et al., 2007). Mice with a targeted deletion of Fgf14 (Fgf14-KO) recapitulate the deficits of SCA27 patients (Wang et al., 2002). In this animal model, the lack of Fgf14 is responsible for deficits in neuronal excitability of cerebellar granule cells (Goldfarb et al., 2007) and PCs (Shakkottai et al., 2009). Although the impairment of action potential firing in these cells likely plays an important role in ataxic symptoms, recent reports showed that Fgf14 is necessary to preserve proper transmission at the PF-PC synapse. In fact, in granule cell-PC mixed cultures in which Fgf14 has been deleted or knocked down, PFs show a profound suppression of neurotransmitter release (Yan et al., 2013), correlated with a deficit of voltage-gated $\mathrm{Ca}^{2+}$ currents in PF presynaptic varicosities (Yan et al., 2013). However, the onset of SCA27 in some patients is in the adult age, suggesting that, in the cerebellum, the PF-PC synapse is less severely affected than in culture and that other mechanisms might be involved. Indeed, in ex vivo cerebellar slices from Fgf14-KO mice, the efficacy of the PF-PC synapse is only reduced by about $40 \%$ (Tempia et al., 2015). Also in this case, the mechanism is presynaptic, so that, with the repetitive firing of PFs, synaptic facilitation is remarkably enhanced. It is likely that such synaptic facilitation compensates in great part for the deficit in neurotransmitter release by the first spike of a burst of activity. In fact, the activation of $\mathrm{PC} \mathrm{mGlu}_{1}$ receptors by high frequency firing of PFs is not affected in Fgf14-KO mice (Tempia et al., 2015).

\section{Autism Spectrum Disorders}

Regarding psychiatric disorders, the cerebellum has been strongly implied in Autism Spectrum Disorders (ASD). In fact, cerebellar malformation and PC loss are frequent findings in the analysis of autoptic material from ASD patients (Bauman and Kemper, 2005; Amaral et al., 2008). In addition, the cerebellar injury is associated with a higher incidence of ASD (Limperopoulos et al., 2007). A central role of PCs in ASD has been confirmed by recent studies in animal models. Some of these studies have even showed that a genetic modification specifically restricted to PCs is sufficient to cause symptoms related to ASD. The main findings, regarding the PF-PC synapse, of studies of PC-selective mutants are summarized in Figure 4.

The role of PCs in ASDs was first examined in a model of tuberous sclerosis, a complex disease associated with a high incidence of autism (Jeste et al., 2008). Tuberous sclerosis
Complex 1 (TSC1), which is one of the main genes mutated in tuberous sclerosis, was selectively knocked out in cerebellar PCs (Tsai et al., 2012). Both homozygous and heterozygous mice showed social interaction deficits and repetitive behavior, reproducing salient features of patients with ASD. Moreover, while homozygous mice also displayed ataxia, heterozygotes presented autistic trait but normal motor performance. Although heterozygous Tsc1 mutant mice had no PC loss, the PC dendritic tree had an aberrant increase in the density of spines. It is interesting to note that in this model of ASD the efficacy of both PF-PC and CF-PC synapses was intact, but PCs showed a reduced rate of action potential firing. Thus, in this animal model, the alteration of dendritic spines was not accompanied by changes in the synaptic input impinging onto PCs, suggesting that the impairment in the output signals to the DCN is due to a deficiency in the intrinsic membrane properties regulating the generation of action potentials. This deficit and the associated behavioral symptoms could be ascribed to the loss of inhibition of mammalian target of rapamycin (mTOR) by Tsc1. In fact, an inhibitor of mTOR (rapamycin) was able to revert the autistic symptoms and the pathological alterations.

A second study examined the role of phosphatase and tensin homolog missing on chromosome 10 (PTEN), a gene involved in $5-10 \%$ cases of autism ( $\mathrm{Li}$ et al., 1997; McBride et al., 2010). PTEN negatively regulates PI3K-AKT signaling, which controls in parallel mTOR and GSK3 pathways (Song et al., 2012). A selective deletion of Pten in PCs was sufficient to cause autistic-like behaviors (Cupolillo et al., 2016). These Pten mutant mice displayed PC soma enlargement, thicker dendrites with swellings and axonal torpedoes. While at 4 months the PC number was the same in Pten mutant and wild-type controls, at 6 months of age the mutant PCs showed a $50 \%$ reduction in number. Behavioral and electrophysiological analyses were performed at 3-4 months of age, when PC death was not yet evident and motor performance was still normal. Pten mutant mice displayed deficits in social interaction and repetitive behavior, suggestive of autistic symptoms. PC action potential firing was significantly reduced, similarly to Tsc1 mutants. However, the efficacy of the PF-PC synapse was strongly increased to double level relative to controls, through a postsynaptic mechanism. Interestingly, the CF-PC synapse was reduced via a presynaptic mechanism, as a consequence of the altered PF input or as a tentative compensation aimed at normalizing the balance of excitatory inputs to Pten mutant PCs.

A third study (Peter et al., 2006) focused on the postsynaptic scaffolding protein SHANK2, which is strongly linked to ASD. In accordance with ASD symptoms, mice with a PC-specific deletion of Shank2 showed impaired sociability, and behavioral inflexibility in the form of increased perseverance in a T-maze test. In contrast to the other two PC-selective ASD models, PC-Shank2 knockout mice had a normal PC firing frequency, but in vivo recordings disclosed an aberrant irregularity of PC discharge. The synaptic function was not investigated in PC-Shank2 knockout animals, but only in mice with a global Shank2 deletion, which showed normal PF-PC 


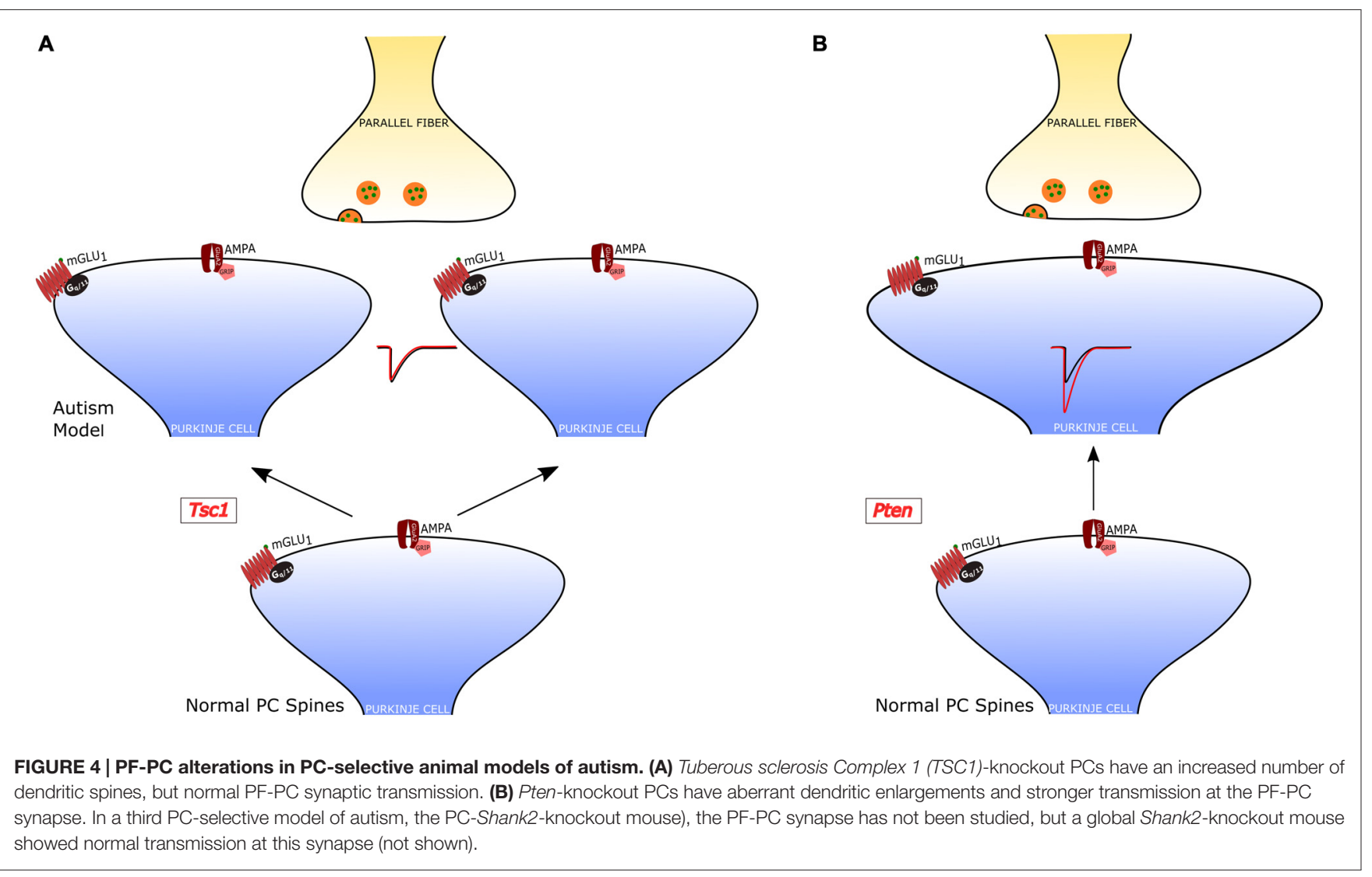

synaptic transmission but an increased frequency of postsynaptic inhibitory currents and impaired LTP of the PF-PC synapse associated with a deficit in intrinsic PC plasticity.

These three studies have in common the finding of an alteration of PC action potential firing. In Tsc1 and Pten PC-selective knockout mice the frequency was reduced, while the lack of Shank2 caused an increased irregularity of firing. These results, taken together, suggest that a preserved PC firing might be necessary to avoid ASD-related symptoms. Other features were present in some, but not in all models, like the alteration of the dendritic morphology, consisting of an increased number of spines or dendritic thickness in Tsc1 and Pten mice, which in Shank2 mice were normal. The role of the PF-PC synapse in ASD remains undefined, although the stronger efficacy in Pten mutants can definitely affect the afferent input signals to PCs and therefore the signal processing. Some of these alterations are likely responsible for autistic symptoms, but in order to know the relative importance of intrinsic properties relative to synaptic efficacy, it would be necessary to understand more about the mechanisms downstream of PCs. For example, optogenetic manipulations of PC firing parameters like frequency or regularity might confirm or reject the hypothesis that such signals play a central role in the pathogenesis of autism. Other relevant open questions include the consequences of an altered output from the cerebellar cortex to the DCN. Finally, we suggest that answers about this topic might arise from studies of the circuits, originating from the cerebellum, involved in the deficits of social communication, repetitive behavior and behavioral inflexibility, which are cardinal symptoms of ASD, reproduced in animal models (Lai et al., 2014).

\section{CONCLUSION}

The PF-PC synapse possesses a pivotal position in the cerebellar network, being the site of maximal signal divergence and convergence. It can integrate incoming signals over different time scales, from millisecond via AMPA receptors to seconds via $\mathrm{mGlu}_{1}$ receptors to days up to years through plastic changes. This privileged role of the PF-PC synapse is paralleled by a variety of mechanisms of dynamic and plastic modulation. Dynamic modulation arises from different diffuse-projection neurotransmitter systems including serotonin, noradrenaline and acetylcholine. The dynamic modulation operates a fine tuning of the gain of data processing at this level. The plasticity of the PF-PC synapse can be viewed as a mechanism to store changes in the efficacy of afferent input signals to the cerebellar cortex so that the gain of each element of the PF-PC matrix can be adjusted to cope with any specific task. Such a mechanism constitutes a critical element of cerebellar motor learning and memory. The physiological importance of the PF-PC synapse explains the consequences in conditions in which it cannot work properly. In fact, alterations of this synapse are encountered in some forms of ataxia (SCA1, 3, 5, 27). The mechanisms 
responsible for the development of ASD are more complex. In fact, at present, it is not clear how the cerebellum is involved and how the dysregulation of the PF-PC synapse contributes to this disease. For both types of disease, ataxia and autism, the full range of physiological mechanisms has not yet been completely investigated. Furthermore, in several cases, a dysfunction of the PF-PC synapse is associated with alterations of PC firing or of

\section{REFERENCES}

Abbott, L. C., and Sotelo, C. (2000). Ultrastructural analysis of catecholaminergic innervation in weaver and normal mouse cerebellar cortices. J. Comp. Neurol. 426, 316-329. doi: 10.1002/1096-9861(20001016)426:2<316::AID-CNE11>3. 3.CO;2-\#

Ady, V., Perroy, J., Tricoire, L., Piochon, C., Dadak, S., Chen, X., et al. (2014). Type 1 metabotropic glutamate receptors (mGlu1) trigger the gating of GluD2 delta glutamate receptors. EMBO Rep. 15, 103-109. doi: 10.1002/embr.201337371

Aiba, A., Kano, M., Chen, C., Stanton, M. E., Fox, G. D., Herrup, K., et al. (1994). Deficient cerebellar long-term depression and impaired motor learning in mGluR1 mutant mice. Cell 79, 377-388. doi: 10.1016/0092-8674(94)90205-4

Albus, J. S. (1971). A theory of cerebellar function. Math. Biosci. 10, 25-61. doi: 10. 1016/0025-5564(71)90051-4

Amaral, D. G., Schumann, C. M., and Nordahl, C. W. (2008). Neuroanatomy of autism. Trends Neurosci. 31, 137-145. doi: 10.1016/j.tins.2007.12.005

Andre, P., Pompeiano, O., Manzoni, D., and D'Ascanio, P. (1992). Muscarinic receptors in the cerebellar vermis modulate the gain of the vestibulospinal reflexes in decerebrate cats. Arch. Ital. Biol. 130, 213-245.

Anggono, V., and Huganir, R. L. (2012). Regulation of AMPA receptor trafficking and synaptic plasticity. Curr. Opin. Neurobiol. 22, 461-469. doi: 10.1016/j.conb. 2011.12.006

Arata, A., and Ito, M. (2004). Purkinje cell functions in the in vitro cerebellum isolated from neonatal rats in a block with the pons and medulla. Neurosci. Res. 50, 361-367. doi: 10.1016/j.neures.2004.08.011

Armbrust, K. R., Wang, X., Hathorn, T. J., Cramer, S. W., Chen, G., Zu, T., et al. (2014). Mutant $\beta$-III spectrin causes mGluR1 $\alpha$ mislocalization and functional deficits in a mouse model of spinocerebellar ataxia type 5. J. Neurosci. 34, 9891-9904. doi: 10.1523/JNEUROSCI.0876-14.2014

Aston-Jones, G., Rajkowski, J., and Cohen, J. (1999). Role of locus coeruleus in attention and behavioral flexibility. Biol. Psychiatry 46, 1309-1320. doi: 10 . 1016/s0006-3223(99)00140-7

Azevedo, F. A., Carvalho, L. R., Grinberg, L. T., Farfel, J. M., Ferretti, R. E., Leite, R. E., et al. (2009). Equal numbers of neuronal and nonneuronal cells make the human brain an isometrically scaled-up primate brain. J. Comp. Neurol. 513, 532-541. doi: 10.1002/cne.21974

Barmack, N. H., Baughman, R. W., Eckenstein, F. P., and Shojaku, H. (1992). Secondary vestibular cholinergic projection to the cerebellum of rabbit and rat as revealed by choline acetyltransferase immunohistochemistry, retrograde and orthograde tracers. J. Comp. Neurol. 317, 250-270. doi: 10.1002/cne.9031 70304

Batchelor, A. M., and Garthwaite, J. (1993). Novel synaptic potentials in cerebellar Purkinje cells: probable mediation by metabotropic glutamate receptors. Neuropharmacology 32, 11-20. doi: 10.1016/0028-3908(93)90124-1

Batchelor, A. M., and Garthwaite, J. (1997). Frequency detection and temporally dispersed synaptic signal association through a metabotropic glutamate receptor pathway. Nature 385, 74-77. doi: 10.1038/385074a0

Batchelor, A. M., Madge, D. J., and Garthwaite, J. (1994). Synaptic activation of metabotropic glutamate receptors in the parallel fibre-Purkinje cell pathway in rat cerebellar slices. Neuroscience 63, 911-915. doi: 10.1016/03064522(94)90558-4

Bauman, M. L., and Kemper, T. L. (2005). Neuroanatomic observations of the brain in autism: a review and future directions. Int. J. Dev. Neurosci. 23, 183-187. doi: 10.1016/j.ijdevneu.2004.09.006

Belmeguenai, A., and Hansel, C. (2005). A role for protein phosphatases 1, 2A and 2B in cerebellar long-term potentiation. J. Neurosci. 25, 10768-10772. doi: 10. 1523/jneurosci.2876-05.2005 other synaptic contacts. Future experiments need to clarify the specific role of each of these mechanisms in the pathogenesis of cerebellum-dependent diseases.

\section{AUTHOR CONTRIBUTIONS}

EH, FT, PL, MCM wrote this manuscript.

Belmeguenai, A., Hosy, E., Bengtsson, F., Pedroarena, C. M., Piochon, C. Teuling, E., et al. (2010). Intrinsic plasticity complements long-term potentiation in parallel fiber input gain control in cerebellar Purkinje cells. J. Neurosci. 30, 13630-13643. doi: 10.1523/JNEUROSCI.3226-10.2010

Bishop, G. A., and Ho, R. H. (1985). The distribution and origin of serotonin immunoreactivity in the rat cerebellum. Brain Res. 331, 195-207. doi: 10. 1016/0006-8993(85)91545-8

Brown, S. P., Brenowitz, S. D., and Regehr, W. G. (2003). Brief presynaptic bursts evoke synapse-specific retrograde inhibition mediated by endogenous cannabinoids. Nat. Neurosci. 6, 1048-1057. doi: 10.1038/nn1126

Brunel, N., Hakim, V., Isope, P., Nadal, J. P., and Barbour, B. (2004). Optimal information storage and the distribution of synaptic weights: perceptron versus Purkinje cell. Neuron 43, 745-757. doi: 10.1016/s0896-6273(04)00528-8

Brusse, E., de Koning, I., Maat-Kievit, A., Oostra, B. A., Heutink, P., and van Swieten, J. C. (2006). Spinocerebellar ataxia associated with a mutation in the fibroblast growth factor 14 gene (SCA27): a new phenotype. Mov. Disord. 21, 396-401. doi: 10.1002/mds.20708

Canepari, M., Papageorgiou, G., Corrie, J. E., Watkins, C., and Ogden, D. (2001). The conductance underlying the parallel fibre slow EPSP in rat cerebellar Purkinje neurones studied with photolytic release of L-glutamate. J. Physiol. 533, 765-772. doi: 10.1111/j.1469-7793.2001.00765.x

Carey, M. R., and Regehr, W. G. (2009). Noradrenergic control of associative synaptic plasticity by selective modulation of instructive signals. Neuron 62, 112-122. doi: 10.1016/j.neuron.2009.02.022

Cartford, M. C., Allgeier, C. A., and Bickford, P. C. (2002). The effects of $\beta$-noradrenergic receptor blockade on acquisition of eyeblink conditioning in 3-month-old F344 rats. Neurobiol. Learn. Mem. 78, 246-257. doi: 10. 1006/nlme.2002.4063

Chadderton, P., Margrie, T. W., and Häusser, M. (2004). Integration of quanta in cerebellar granule cells during sensory processing. Nature 428, 856-860. doi: 10. 1038/nature02442

Chan-Palay, V. (1975). Fine structure of labelled axons in the cerebellar cortex and nuclei of rodents and primates after intraventricular infusions with tritiated serotonin. Anat. Embryol. (Berl) 148, 235-265. doi: 10.1007/bf003 19846

Chen, C., and Regehr, W. G. (1997). The mechanism of cAMP-mediated enhancement at a cerebellar synapse. J. Neurosci. 17, 8687-8694.

Clayton, E. C., Rajkowski, J., Cohen, J. D., and Aston-Jones, G. (2004). Phasic activation of monkey locus ceruleus neurons by simple decisions in a forced-choice task. J. Neurosci. 24, 9914-9920. doi: 10.1523/JNEUROSCI.244604.2004

Conquet, F., Bashir, Z. I., Davies, C. H., Daniel, H., Ferraguti, F., Bordi, F., et al. (1994). Motor deficit and impairment of synaptic plasticity in mice lacking mGluR1. Nature 372, 237-243. doi: 10.1038/372237a0

Cupolillo, D., Hoxha, E., Faralli, A., De Luca, A., Rossi, F., Tempia, F., et al. (2016). Autistic-like traits and cerebellar dysfunction in Purkinje cell PTEN knock-out mice. Neuropsychopharmacology 41, 1457-1466. doi: 10.1038/npp. 2015.339

D’Angelo, E., and Casali, S. (2013). Seeking a unified framework for cerebellar function and dysfunction: from circuit operations to cognition. Front. Neural Circuits 6:116. doi: 10.3389/fncir.2012.00116

D’Angelo, E., Mapelli, L., Casellato, C., Garrido, J. A., Luque, N., Monaco, J., et al. (2016). Distributed circuit plasticity: new clues for the cerebellar mechanisms of learning. Cerebellum 15, 139-151. doi: 10.1007/s12311-015-0711-7

Durr, A. (2010). Autosomal dominant cerebellar ataxias: polyglutamine expansions and beyond. Lancet Neurol. 9, 885-894. doi: 10.1016/s14744422(10)70183-6 
Dzubay, J. A., and Otis, T. S. (2002). Climbing fiber activation of metabotropic glutamate receptors on cerebellar purkinje neurons. Neuron 36, 1159-1167. doi: 10.1016/s0896-6273(02)01052-8

Eastwood, S. L., Burnet, P. W., Gittins, R., Baker, K., and Harrison, P. J. (2001). Expression of serotonin $5-\mathrm{HT}^{2 A}$ receptors in the human cerebellum and alterations in schizophrenia. Synapse 42, 104-114. doi: 10.1002/syn.1106

Eccles, J. C., Llinás, R., and Sasaki, K. (1966). The mossy fibre-granule cell relay of the cerebellum and its inhibitory control by Golgi cells. Exp. Brain Res. 1, 82-101. doi: 10.1007/bf00235211

Eilers, J., Augustine, G. J., and Konnerth, A. (1995). Subthreshold synaptic Ca ${ }^{2+}$ signalling in fine dendrites and spines of cerebellar Purkinje neurons. Nature 373, 155-158. doi: 10.1038/373155a0

Ekerot, C. F., and Jörntell, H. (2001). Parallel fibre receptive fields of Purkinje cells and interneurons are climbing fibre-specific. Eur. J. Neurosci. 13, 1303-1310. doi: 10.1046/j.0953-816x.2001.01499.x

Finch, E. A., and Augustine, G. J. (1998). Local calcium signalling by inositol1,4,5-trisphosphate in Purkinje cell dendrites. Nature 396, 753-756. doi: 10. $1038 / 25541$

Gao, Z., van Beugen, B. J., and De Zeeuw, C. I. (2012). Distributed synergistic plasticity and cerebellar learning. Nat. Rev. Neurosci. 13, 619-635. doi: 10. 1038/nrn3312

Geurts, F. J., De Schutter, E., and Timmermans, J. P. (2002). Localization of 5-HT2A, 5-HT3, 5-HT5A and 5-HT7 receptor-like immunoreactivity in the rat cerebellum. J. Chem. Neuroanat. 24, 65-74. doi: 10.1016/s0891-0618(02) 00020-0

Goldfarb, M., Schoorlemmer, J., Williams, A., Diwakar, S., Wang, Q., Huang, X., et al. (2007). Fibroblast growth factor homologous factors control neuronal excitability through modulation of voltage-gated sodium channels. Neuron 55 , 449-463. doi: 10.1016/j.neuron.2007.07.006

Gould, T. J. (1998). $\beta$-adrenergic involvement in acquisition vs. extinction of a classically conditioned eye blink response in rabbits. Brain Res. 780, 174-177. doi: 10.1016/s0006-8993(97)01305-x

Grasselli, G., He, Q., Wan, V., Adelman, J. P., Ohtsuki, G., and Hansel, C. (2016). Activity-dependent plasticity of spike pauses in cerebellar Purkinje cells. Cell Rep. 14, 2546-2553. doi: 10.1016/j.celrep.2016.02.054

Hanley, J. G. (2008). PICK1: a multi-talented modulator of AMPA receptor trafficking. Pharmacol. Ther. 118, 152-160. doi: 10.1016/j.pharmthera.2008. 02.002

Hartmann, J., Blum, R., Kovalchuk, Y., Adelsberger, H., Kuner, R., Durand, G. M., et al. (2004). Distinct roles of $\mathrm{G} \alpha^{\mathrm{q}}$ and $\mathrm{G} \alpha^{11}$ for Purkinje cell signaling and motor behavior. J. Neurosci. 24, 5119-5130. doi: 10.1523/jneurosci.4193-03. 2004

Hartmann, J., Dragicevic, E., Adelsberger, H., Henning, H. A., Sumser, M., Abramowitz, J., et al. (2008). TRPC3 channels are required for synaptic transmission and motor coordination. Neuron 59, 392-398. doi: 10.1016/j. neuron.2008.06.009

Harvey, R. J., and Napper, R. M. (1988). Quantitative study of granule and Purkinje cells in the cerebellar cortex of the rat. J. Comp. Neurol. 274, 151-157. doi: 10. 1002/cne.902740202

Herold, S., Hecker, C., Deitmer, J. W., and Brockhaus, J. (2005). $\alpha 1$-Adrenergic modulation of synaptic input to Purkinje neurons in rat cerebellar brain slices. J. Neurosci. Res. 82, 571-579. doi: 10.1002/jnr.20660

Hirai, H. (2001). Modification of AMPA receptor clustering regulates cerebellar synaptic plasticity. Neurosci. Res. 39, 261-267. doi: 10.1016/s01680102(00)00237-6

Hirono, M., Konishi, S., and Yoshioka, T. (1998). Phospholipase C-independent group I metabotropic glutamate receptor-mediated inward current in mouse Purkinje cells. Biochem. Biophys. Res. Commun. 251, 753-758. doi: 10. 1006/bbrc. 1998.9465

Hirono, M., Matsunaga, W., Chimura, T., and Obata, K. (2008). Developmental enhancement of alpha2- adrenoceptor-mediated suppression of inhibitory synaptic transmission onto mouse cerebellar Purkinje cells. Neuroscience 156, 143-154. doi: 10.1016/j.neuroscience.2008.07.018

Hirono, M., Sugiyama, T., Kishimoto, Y., Sakai, I., Miyazawa, T., Kishio, M., et al. (2001). Phospholipase C $\beta 4$ and protein kinase $C \alpha$ and/or protein kinase C $\beta I$ are involved in the induction of long term depression in cerebellar Purkinje cells. J. Biol. Chem. 276, 45236-45242. doi: 10.1074/jbc.M105413200

Hoffer, B. J., Siggins, G. R., and Bloom, F. E. (1971). Studies on norepinephrine-containing afferents to Purkinje cells of rat cerebellum.
II. Sensitivity of Purkinje cells to norepinephrine and related substances administered by microiontophoresis. Brain Res. 25, 523-534. doi: 10. 1016/0006-8993(71)90458-6

Hollmann, M., Hartley, M., and Heinemann, S. (1991). Ca2 ${ }^{+}$permeability of KAAMPA - gated glutamate receptor channels depends on subunit composition. Science 252, 851-853. doi: 10.1126/science.1709304

Huang, C., Gammon, S. J., Dieterle, M., Huang, R. H., Likins, L., and Ricklefs, R. E. (2014). Dramatic increases in number of cerebellar granule-cell-Purkinje-cell synapses across several mammals. Mamm. Biol. 79, 163-169. doi: 10.1016/j. mambio.2013.12.003

Hume, R. I., Dingledine, R., and Heinemann, S. F. (1991). Identification of a site in glutamate receptor subunits that controls calcium permeability. Science 253 , 1028-1031. doi: 10.1126/science. 1653450

Ichise, T., Kano, M., Hashimoto, K., Yanagihara, D., Nakao, K., Shigemoto, R., et al. (2000). mGluR1 in cerebellar Purkinje cells essential for long-term depression, synapse elimination and motor coordination. Science 288, 1832-1835. doi: 10.1126/science.288.5472.1832

Isope, P., and Barbour, B. (2002). Properties of unitary granule cell $\rightarrow$ Purkinje cell synapses in adult rat cerebellar slices. J. Neurosci. 22, 9668-9678.

Ito, M. (1982). Cerebellar control of the vestibulo-ocular reflex: around the flocculus hypothesis. Annu. Rev. Neurosci. 5, 275-296. doi: 10.1146/annurev. ne.05.030182.001423

Ito, M. (1984). The Cerebellum and Neural Control. New York, NY: Raven Press.

Ito, M. (1989). Long-term depression. Annu. Rev. Neurosci. 12, 85-102. doi: 10. 1146/annurev.ne.12.030189.000505

Ito, M. (2001). Cerebellar long-term depression: characterization, signal transduction and functional roles. Physiol. Rev. 81, 1143-1195.

Ito, M. (2002). The molecular organization of cerebellar long-term depression. Nat. Rev. Neurosci. 3, 896-902. doi: 10.1038/nrn962

Ito, M. (2006). Cerebellar circuitry as a neuronal machine. Prog. Neurobiol. 78, 272-303. doi: 10.1016/j.pneurobio.2006.02.006

Ito, M., Sakurai, M., and Tongroach, P. (1982). Climbing fibre induced depression of both mossy fibre responsiveness and glutamate sensitivity of cerebellar Purkinje cells. J. Physiol. 324, 113-134. doi: 10.1113/jphysiol.1982. sp014103

Ito, H. T., and Schuman, E. M. (2008). Frequency-dependent signal transmission and modulation by neuromodulators. Front. Neurosci. 2, 138-144. doi: 10. 3389/neuro.01.027.2008

Jaarsma, D., Ruigrok, T. J., Caffé, R., Cozzari, C., Levey, A. I., Mugnaini, E., et al. (1997). Cholinergic innervation and receptors in the cerebellum. Prog. Brain Res. 114, 67-96. doi: 10.1016/s0079-6123(08)63359-2

Jacoby, S., Sims, R. E., and Hartell, N. A. (2001). Nitric oxide is required for the induction and heterosynaptic spread of long-term potentiation in rat cerebellar slices. J. Physiol. 535, 825-839. doi: 10.1111/j.1469-7793.2001.t01-1-00825.x

Jeste, S. S., Sahin, M., Bolton, P., Ploubidis, G. B., and Humphrey, A. (2008). Characterization of autism in young children with tuberous sclerosis complex. J. Child Neurol. 23, 520-525. doi: 10.1177/0883073807309788

Joiner, M. L., Lisé, M. F., Yuen, E. Y., Kam, A. Y., Zhang, M., Hall, D. D., et al. (2010). Assembly of a $\beta_{2}$-adrenergic receptor-GluR1 signalling complex for localized cAMP signalling. EMBO J. 29, 482-495. doi: 10.1038/emboj.2009.344

Kaeser, P. S., Kwon, H. B., Chiu, C. Q., Deng, L., Castillo, P. E., and Südhof, T. C. (2008). RIM1 $\alpha$ and RIM1 $\beta$ are synthesized from distinct promoters of the RIM1 gene to mediate differential but overlapping synaptic functions. J. Neurosci. 28, 13435-13447. doi: 10.1523/JNEUROSCI.3235-08.2008

Kaneko, W. M., Britto, L. R., Lindstrom, J. M., and Karten, H. J. (1998). Distribution of the alpha7 nicotinic acetylcholine receptor subunit in the developing chick cerebellum. Dev. Brain Res. 105, 141-145. doi: 10.1016/s01653806(97)00160-0

Kano, M., Hashimoto, K., and Tabata, T. (2008). Type-1 metabotropic glutamate receptor in cerebellar Purkinje cells: a key molecule responsible for long-term depression, endocannabinoid signalling and synapse elimination. Philos. Trans. R. Soc. Lond. B Biol. Sci. 363, 2173-2186. doi: 10.1098/rstb. 2008.2270

Kim, S. J., Kim, Y. S., Yuan, J. P., Petralia, R. S., Worley, P. F., and Linden, D. J. (2003). Activation of the TRPC1 cation channel by metabotropic glutamate receptor mGluR1. Nature 426, 285-291. doi: 10.1038/nature02162

Kimpo, R. R., Rinaldi, J. M., Kim, C. K., Payne, H. L., and Raymond, J. L. (2014). Gating of neural error signals during motor learning. Elife 3:e02076. doi: 10 7554/eLife.02076 
Kish, S. J., Shannak, K. S., and Hornykiewicz, O. (1984b). Reduction of noradrenaline in cerebellum of patients with olivopontocerebellar atrophy. J. Neurochem. 42, 1476-1478. doi: 10.1111/j.1471-4159.1984.tb02813.x

Kish, S. J., Shannak, K. S., Rajput, A. H., Gilbert, J. J., and Hornykiewicz, O. (1984a). Cerebellar norepinephrine in patients with Parkinson's disease and control subjects. Arch. Neurol. 41, 612-614. doi: 10.1001/archneur.1984. 04210080020007

Knöpfel, T., Anchisi, D., Alojado, M. E., Tempia, F., and Strata, P. (2000). Elevation of intradendritic sodium concentration mediated by synaptic activation of metabotropic glutamate receptors in cerebellar Purkinje cells. Eur. J. Neurosci. 12, 2199-2204. doi: 10.1046/j.1460-9568.2000.00122.x

Konnerth, A., Dreessen, J., and Augustine, G. J. (1992). Brief dendritic calcium signals initiate long-lasting synaptic depression in cerebellar Purkinje cells. Proc. Natl. Acad. Sci. U S A 89, 7051-7055. doi: 10.1073/pnas.89.15.7051

Konno, A., Shuvaev, A. N., Miyake, N., Miyake, K., Iizuka, A., Matsuura, S., et al. (2014). Mutant ataxin-3 with an abnormally expanded polyglutamine chain disrupts dendritic development and metabotropic glutamate receptor signaling in mouse cerebellar Purkinje cells. Cerebellum 13, 29-41. doi: 10.1007/s12311013-0516-5

Krupa, D. J., and Thompson, R. F. (1997). Reversible inactivation of the cerebellar interpositus nucleus completely prevents acquisition of the classically conditioned eye-blink response. Learn. Mem. 3, 545-556. doi: 10.1101/lm.3.6. 545

Lai, M. C., Lombardo, M. V., and Baron-Cohen, S. (2014). Autism. Lancet 383, 96-910. doi: 10.1016/S0140-6736(13)61539-1

Le Marec, N., Ase, A. R., Botez-Marquard, T., Marchand, L., Reader, T. A., and Lalonde, R. (2001). Behavioral and biochemical effects of L-tryptophan and buspirone in a model of cerebellar atrophy. Pharmacol. Biochem. Behav. 69, 333-342. doi: 10.1016/s0091-3057(01)00536-6

Lee, M., Martin-Ruiz, C., Graham, A., Court, J., Jaros, E., Perry, R., et al. (2002). Nicotinic receptor abnormalities in the cerebellar cortex in autism. Brain 125, 1483-1495. doi: 10.1093/brain/awf160

Lee, D., Yamamoto, Y., Kim, E., and Tanaka-Yamamoto, K. (2015). Functional and physical interaction of diacylglycerol kinase $\zeta$ with protein kinase $\mathrm{C} \alpha$ is required for cerebellar long-term depression. J. Neurosci. 35, 15453-15465. doi: 10.1523/JNEUROSCI.1991-15.2015

Leitges, M., Kovac, J., Plomann, M., and Linden, D. J. (2004). A unique PDZ ligand in PKC $\alpha$ confers induction of cerebellar long-term synaptic depression. Neuron 44, 585-594. doi: 10.1016/j.neuron.2004.10.024

Li, J., Yen, C., Liaw, D., Podsypanina, K., Bose, S., Wang, S. I., et al. (1997). PTEN, a putative protein tyrosine phosphatase gene mutated in human brain, breast and prostate cancer. Science 275, 1943-1947. doi: 10.1126/science.275.53 08.1943

Li, X., Zhu, W., Roh, M. S., Friedman, A. B., Rosborough, K., and Jope, R. S. (2004). In vivo regulation of glycogen synthase kinase- $3 \beta$ (GSK3 $\beta$ ) by serotonergic activity in mouse brain. Neuropsychopharmacology 29, 1426-1431. doi: 10. 1038/sj.npp.1300439

Limperopoulos, C., Bassan, H., Gauvreau, K., Robertson, R. L. Jr., Sullivan, N. R., Benson, C. B., et al. (2007). Does cerebellar injury in premature infants contribute to the high prevalence of long-term cognitive, learning and behavioral disability in survivors? Pediatrics $120,584-593$. doi: 10.1542/peds. 2007-1041

Lippiello, P., Hoxha, E., Speranza, L., Volpicelli, F., Ferraro, A., Leopoldo, M., et al. (2016). The 5-HT7 receptor triggers cerebellar long-term synaptic depression via PKC-MAPK. Neuropharmacology 101, 426-438. doi: 10.1016/j. neuropharm.2015.10.019

Lippiello, P., Hoxha, E., Volpicelli, F., Lo Duca, G., Tempia, F., and Miniaci, M. C. (2015). Noradrenergic modulation of the parallel fiber-Purkinje cell synapse in mouse cerebellum. Neuropharmacology 89, 33-42. doi: 10.1016/j.neuropharm. 2014.08.016

Maejima, T., Hashimoto, K., Yoshida, T., Aiba, A., and Kano, M. (2001). Presynaptic inhibition caused by retrograde signal from metabotropic glutamate to cannabinoid receptors. Neuron 31, 463-475. doi: 10.1016/s08966273(01)00375-0

Maejima, T., Oka, S., Hashimotodani, Y., Ohno-Shosaku, T., Aiba, A., Wu, D., et al. (2005). Synaptically driven endocannabinoid release requires $\mathrm{Ca}^{2+}$. assisted metabotropic glutamate receptor subtype 1 to phospholipase $\mathrm{C}$ $\beta 4$ signaling cascade in the cerebellum. J. Neurosci. 25, 6826-6835. doi: 10. 1523/JNEUROSCI.0945-05.2005
Mapelli, L., Pagani, M., Garrido, J. A., and D’Angelo, E. (2015). Integrated plasticity at inhibitory and excitatory synapses in the cerebellar circuit. Front. Cell. Neurosci. 9:169. doi: 10.3389/fncel.2015.00169

Marr, D. (1969). A theory of cerebellar cortex. J. Physiol. 202, 437-470. doi: 10. 1113/jphysiol.1969.sp008820

Matsumoto, M., Nakagawa, T., Inoue, T., Nagata, E., Tanaka, K., Takano, H., et al. (1996). Ataxia and epileptic seizures in mice lacking type 1 inositol 1,4,5trisphosphate receptor. Nature 379, 168-171. doi: 10.1038/379168a0

Maura, G., Ricchetti, A., and Raiteri, M. (1986). Serotonin inhibits the depolarization-evoked release of endogenous glutamate from rat cerebellar nerve endings. Neurosci. Lett. 67, 218-222. doi: 10.1016/0304-3940(86) 90401-5

McBride, K. L., Varga, E. A., Pastore, M. T., Prior, T. W., Manickam, K., Atkin, J. F., et al. (2010). Confirmation study of PTEN mutations among individuals with autism or developmental delays/mental retardation and macrocephaly. Autism. Res. 3, 137-141. doi: 10.1002/aur.132

Mitoma, H., Kobayashi, T., Song, S. Y., and Konishi, S. (1994). Enhancement by serotonin of GABA-mediated inhibitory synaptic currents in rat cerebellar Purkinje cells. Neurosci. Lett. 173, 127-130. doi: 10.1016/0304-3940(94) 90165-1

Mitoma, H., and Konishi, S. (1999). Monoaminergic long-term facilitation of GABA- mediated inhibitory transmission at cerebellar synapses. Neuroscience 88, 871-883. doi: 10.1016/s0306-4522(98)00260-7

Miyakawa, H., Lev-Ram, V., Lasser-Ross, N., and Ross, W. N. (1992). Calcium transients evoked by climbing fiber and parallel fiber synaptic inputs in guinea pig cerebellar Purkinje neurons. J. Neurophysiol. 68, 1178-1189.

Miyashita, Y., and Watanabe, E. (1984). Loss of vision-guided adaptation of the vestibulo-ocular reflex after depletion of brain serotonin in the rabbit. Neurosci. Lett. 51, 177-182. doi: 10.1016/0304-3940(84)90547-0

Miyata, M., Kim, H. T., Hashimoto, K., Lee, T. K., Cho, S. Y., Jiang, H., et al. (2001). Deficient long-term synaptic depression in the rostral cerebellum correlated with impaired motor learning in phospholipase C beta4 mutant mice. Eur. J. Neurosci. 13, 1945-1954. doi: 10.1046/j.0953-816x.2001.01570.x

Myoga, M. H., and Regehr, W. G. (2011). Calcium microdomains near R-type calcium channels control the induction of presynaptic long-term potentiation at parallel fiber to purkinje cell synapses. J. Neurosci. 31, 5235-5243. doi: 10. 1523/JNEUROSCI.5252-10.2011

Napper, R. M., and Harvey, R. J. (1988). Number of parallel fiber synapses on an individual Purkinje cell in the cerebellum of the rat. J. Comp. Neurol. 274, 168-177. doi: 10.1002/cne.902740204

Notartomaso, S., Zappulla, C., Biagioni, F., Cannella, M., Bucci, D., Mascio, G. et al. (2013). Pharmacological enhancement of mGlul metabotropic glutamate receptors causes a prolonged symptomatic benefit in a mouse model of spinocerebellar ataxia type 1. Mol. Brain 6:48. doi: 10.1186/1756-6606-6-48

Nusser, Z., Mulvihill, E., Streit, P., and Somogyi, P. (1994). Subsynaptic segregation of metabotropic and ionotropic glutamate receptors as revealed by immunogold localization. Neuroscience 61, 421-427. doi: 10.1016/03064522(94)90421-9

Olson, L., and Fuxe, K. (1971). On the projections from the locus coeruleus noradrenaline neurons: the cerebellar innervation. Brain Res. 28, 165-171. doi: 10.1016/0006-8993(71)90533-6

Oostland, M., Buijink, M. R., Teunisse, G. M., von Oerthel, L., Smidt, M. P., and van Hooft, J. A. (2014). Distinct temporal expression of 5- $\mathrm{HT}_{1 \mathrm{~A}}$ and $5-\mathrm{HT}_{2 \mathrm{~A}}$ receptors on cerebellar granule cells in mice. Cerebellum 13, 491-500. doi: 10. 1007/s12311-014-0565-4

Palay, S. L., and Chan-Palay, V. (1974). Cerebellar Cortex Cytology and Organization. Berlin, Heidelberg, New York, NY: Springer-Verlag.

Papay, R., Gaivin, R., Jha, A., McCune, D. F., McGrath, J. C., Rodrigo, M. C., et al. (2006). Localization of the mouse $\alpha 1 \mathrm{~A}$-adrenergic receptor (AR) in the brain: $\alpha 1 \mathrm{AAR}$ is expressed in neurons, GABAergic in- terneurons and NG2 oligodendrocyte progenitors. J. Comp. Neurol. 497, 209-222. doi: 10. 1002/cne.20992

Papay, R., Gaivin, R., McCune, D. F., Rorabaugh, B. R., Macklin, W. B., McGrath, J. C., et al. (2004). Mouse $\beta 1 B$-adrenergic receptor is expressed in neurons and NG2 oligodendrocytes. J. Comp. Neurol. 478, 1-10. doi: 10. $1002 /$ cne.20215

Pazos, A., and Palacios, J. M. (1985). Quantitative autoradiographic mapping of serotonin receptors in the rat brain. I. Serotonin-1 receptors. Brain Res. 346, 205-230. doi: 10.1016/0006-8993(85)90856-x 
Peter, S., Ten Brinke, M. M., Stedehouder, J., Reinelt, C. M., Wu, B., Zhou, H., et al. (2006). Dysfunctional cerebellar Purkinje cells contribute to autism-like behaviour in Shank2-deficient mice. Nat. Commun. 7:12627. doi: $10.1038 /$ ncomms 12627

Power, E. M., Morales, A., and Empson, R. M. (2016). Prolonged type 1 metabotropic glutamate receptor dependent synaptic signaling contributes to spino-cerebellar ataxia type 1. J. Neurosci. 36, 4910-4916. doi: 10. 1523/JNEUROSCI.3953-15.2016

Ramakrishnan, K. B., Voges, K., De Propris, L., De Zeeuw, C. I., and D’Angelo, E. (2016). Tactile stimulation evokes long-lasting potentiation of Purkinje cell discharge in vivo. Front. Cell. Neurosci. 10:36. doi: 10.3389/fncel.2016. 00036

Rancz, E. A., and Häusser, M. (2006). Dendritic calcium spikes are tunable triggers of cannabinoid release and short-term synaptic plasticity in cerebellar Purkinje neurons. J. Neurosci. 26, 5428-5437. doi: 10.1523/jneurosci.528405.2006

Rinaldo, L., and Hansel, C. (2013). Muscarinic acetylcholine receptor activation blocks long-term potentiation at cerebellar parallel fiber-Purkinje cell synapses via cannabinoid signaling. Proc. Natl. Acad. Sci. U S A 110, 11181-11186. doi: $10.1073 /$ pnas. 1221803110

Rossi, D. J., Hamann, M., and Attwell, D. (2003). Multiple modes of GABAergic in- hibition of rat cerebellar granule cells. J. Physiol. 548, 97-110. doi: 10. 1113/jphysiol.2002.036459

Sacchetti, B., Scelfo, B., Tempia, F., and Strata, P. (2004). Long-term synaptic changes induced in the cerebellar cortex by fear conditioning. Neuron 42, 973-982. doi: 10.1016/j.neuron.2004.05.012

Saitow, F., and Konishi, S. (2000). Excitability increase induced by $\beta$-adrenergic receptor-mediated activation of hyperpolarization-activated cation channels in rat cerebellar basket cells. J. Neurophysiol. 84, 2026-2034.

Sakurai, M. (1987). Synaptic modification of parallel fibre-Purkinje cell transmission in in vitro guinea-pig cerebellar slices. J. Physiol. 394, 463-480. doi: 10.1113/jphysiol.1987.sp016881

Salin, P. A., Malenka, R. C., and Nicoll, R. A. (1996). Cyclic AMP mediates a presynaptic form of LTP at cerebellar parallel fiber synapses. Neuron 16, 797-803. doi: 10.1016/s0896-6273(00)80099-9

Scelfo, B., Sacchetti, B., and Strata, P. (2008). Learning-related long-term potentiation of inhibitory synapses in the cerebellar cortex. Proc. Natl. Acad. Sci. U S A 105, 769-774. doi: 10.1073/pnas.0706342105

Schambra, U. B., Mackensen, G. B., Stafford-Smith, M., Haines, D. E., and Schwinn, D. A. (2005). Neuron specific $\alpha$ adrenergic receptor expression in human cerebellum: implications for emerging cerebellar roles in neurologic disease. Neuroscience 135, 507-523. doi: 10.1016/j.neuroscience.2005.06.021

Schonewille, M., Belmeguenai, A., Koekkoek, S. K., Houtman, S. H., Boele, H. J., van Beugen, B. J., et al. (2010). Purkinje cell-specific knockout of the protein phosphatase PP2B impairs potentiation and cerebellar motor learning. Neuron 67, 618-628. doi: 10.1016/j.neuron.2010.07.009

Schonewille, M., Gao, Z., Boele, H. J., Veloz, M. F., Amerika, W. E., Simek, A. A., et al. (2011). Reevaluating the role of LTD in cerebellar motor learning. Neuron. 70, 43-50. doi: 10.1016/j.neuron.2011.02.044

Schreurs, B. G., Gusev, P. A., Tomsic, D., Alkon, D. L., and Shi, T. (1998). Intracellular correlates of acquisition and long-term memory of classical conditioning in Purkinje cell dendrites in slices of rabbit cerebellar lobule HVI. J. Neurosci. 18, 5498-5507.

Schweighofer, N. (1998). A model of activity dependent formation of cerebellar microzones. Biol. Cybern. 79, 97-107. doi: 10.1007/s004220050462

Schweighofer, N., Doya, K., and Kuroda, S. (2004). Cerebellar aminergic neuromodulation: towards a functional understanding. Brain Res. Rev. 44, 103-116. doi: 10.1016/j.brainresrev.2003.10.004

Serra, H. G., Byam, C. E., Lande, J. D., Tousey, S. K., Zoghbi, H. Y., and Orr, H. T. (2004). Gene profiling links SCA1 pathophysiology to glutamate signaling in Purkinje cells of transgenic mice. Hum. Mol. Genet. 13, 2535-2543. doi: 10. 1093/hmg/ddh268

Shakkottai, V. G., Xiao, M., Xu, L., Wong, M., Nerbonne, J. M., Ornitz, D. M., et al. (2009). FGF14 regulates the intrinsic excitability of cerebellar Purkinje neurons. Neurobiol. Dis. 33, 81-88. doi: 10.1016/j.nbd.2008.09.019

Shimohama, S., Taniguchi, T., Fujiwara, M., and Kameyama, M. (1986). Biochemical characterization of alpha-adrenergic receptors in human brain and changes in Alzheimer-type dementia. J. Neurochem. 47, 1295-1301. doi: 10. 1111/j.1471-4159.1986.tb00753.x
Siggins, G. R., Hoffer, B. J., Oliver, A. P., and Bloom, F. E. (1971). Activation of a central noradrenergic projection to cerebellum. Nature 233, 481-483. doi: 10. 1038/233481a0

Slater, P., Doyle, C. A., and Deakin, J. F. (1998). Abnormal persistence of cerebellar serotonin-1A receptors in schizophrenia suggests failure to regress in neonates. J. Neural Transm. (Vienna) 105, 305-315. doi: 10.1007/s0070200 50060

Sommer, B., Köhler, M., Sprengel, R., and Seeburg, P. H. (1991). RNA editing in brain controls a determinant of ion flow in glutamate-gated channels. Cell 67, 11-19. doi: 10.1016/0092-8674(91)90568-j

Song, M. S., Salmena, L., and Pandolfi, P. P. (2012). The functions and regulation of the PTEN tumour suppressor. Nat. Rev. Mol. Cell Biol. 13, 283-296. doi: 10. 1038/nrm3330

Storm, D. R., Hansel, C., Hacker, B., Parent, A., and Linden, D. J. (1998). Impaired cerebellar long-term potentiation in type I adenylyl cyclase mutant mice. Neuron 20, 1199-1210. doi: 10.1016/s0896-6273(00) 80500-0

Storozheva, Z. I., and Proshin, A. T. (2011). Selective involvement of the neurotransmitter systems of the cerebellum in the mechanisms forming different types of defensive behavior. Neurosci. Behav. Physiol. 41, 964-972. doi: 10.1007/s11055-011-9516-4

Tabata, T., Aiba, A., and Kano, M. (2002). Extracellular calcium controls the dynamic range of neuronal metabotropic glutamate receptor responses. $\mathrm{Mol}$. Cell. Neurosci. 20, 56-68. doi: 10.1006/mcne.2002.1118

Takahashi, M., Kovalchuk, Y., and Attwell, D. (1995). Pre- and postsynaptic determinants of EPSC waveform at cerebellar climbing fiber and parallel fiber to Purkinje cell synapses. J. Neurosci. 15, 5693-5702.

Takechi, H., Eilers, J., and Konnerth, A. (1998). A new class of synaptic response involving calcium release in dendritic spines. Nature 396, 757-760. doi: 10. $1038 / 25547$

Tan, H. S., Collewijn, H., and Van der Steen, J. (1993). Unilateral cholinergic stimulation of the rabbit's cerebellar flocculus: asymmetric effects on optokinetic responses. Exp. Brain Res. 92, 375-384. doi: 10.1007/bf002 29025

Tanaka, K., and Augustine, G. J. (2008). A positive feedback signal transduction loop determines timing of cerebellar long-term depression. Neuron 59, 608-620. doi: 10.1016/j.neuron.2008.06.026

Tanaka, J., Nakagawa, S., Kushiya, E., Yamasaki, M., Fukaya, M., Iwanaga, T., et al. (2000). $G_{q}$ protein alpha subunits $G_{\alpha q}$ and $G_{\alpha 11}$ are localized at postsynaptic extra-junctional membrane of cerebellar Purkinje cells and hippocampal pyramidal cells. Eur. J. Neurosci. 12, 781-792. doi: 10.1046/j.1460-9568.2000. 00959.x

Tempia, F., Alojado, M. E., Strata, P., and Knöpfel, T. (2001). Characterization of the $\mathrm{mGluR}^{1}$-mediated electrical and calcium signaling in Purkinje cells of mouse cerebellar slices. J. Neurophysiol. 86, 1389-1397.

Tempia, F., Hoxha, E., Negro, G., Alshammari, M. A., Alshammari, T. K., PanovaElektronova, N., et al. (2015). Parallel fiber to Purkinje cell synaptic impairment in a mouse model of spinocerebellar ataxia type 27. Front. Cell. Neurosci. 9:205. doi: $10.3389 /$ fncel.2015.00205

Tempia, F., Kano, M., Schneggenburger, R., Schirra, C., Garaschuk, O., Plant, T., et al. (1996). Fractional calcium current through neuronal AMPA-receptor channels with a low calcium permeability. J. Neurosci. 16, 456-466.

Tempia, F., and Konnerth, A. (1994). Calcium requirement of long-term depression and rebound potentiation in cerebellar Purkinje neurons. Semin. Cell. Biol. 5, 243-250. doi: 10.1006/scel.1994.1030

Tempia, F., Miniaci, M. C., Anchisi, D., and Strata, P. (1997). Heterosynaptic interaction in cerebellar Purkinje cells mediated by a metabotropic glutamate receptor. Soc. Neurosci. Abstr. 23:1762.

Tempia, F., Miniaci, M. C., Anchisi, D., and Strata, P. (1998). Postsynaptic current mediated by metabotropic glutamate receptors in cerebellar Purkinje cells. J. Neurophysiol. 80, 520-528.

Trouillas, P., Brudon, F., and Adeleine, P. (1988). Improvement of cerebellar ataxia with levorotatory form of 5-hydroxytryptophan. A double-blind study with quanti- fied data processing. Arch. Neurol. 45, 1217-1222. doi: 10 1001/archneur.1988.00520350055016

Trouillas, P., Serratrice, G., Laplane, D., Rascol, A., Augustin, P., Barroche, G., et al. (1995). Levorotatory form of 5- hydroxytryptophan in Friedreich's ataxia. Results of a double-blind drug-placebo cooperative study. Arch. Neurol. 52, 456-460. doi: 10.1001/archneur.1995.00540290042016 
Tsai, P. T., Hull, C., Chu, Y., Greene-Colozzi, E., Sadowski, A. R., Leech, J. M., et al. (2012). Autistic-like behaviour and cerebellar dysfunction in Purkinje cell Tsc1 mutant mice. Nature. 488, 647-651. doi: 10.1038/nature 11310

Turner, J. R., and Kellar, K. J. (2005). Nicotinic cholinergic receptors in the rat cerebellum: multiple heteromeric subtypes. J. Neurosci. 25, 9258-9265. doi: 10. 1523/jneurosci.2112-05.2005

Valera, A. M., Doussau, F., Poulain, B., Barbour, B., and Isope, P. (2012). Adaptation of granule cell to Purkinje cell synapses to high-frequency transmission. J. Neurosci. 32, 3267-3280. doi: 10.1523/JNEUROSCI.3175-11. 2012

van Beugen, B. J., Gao, Z., Boele, H. J., Hoebeek, F., and De Zeeuw, C. I. (2013). High frequency burst firing of granule cells ensures transmission at the parallel fiber to purkinje cell synapse at the cost of temporal coding. Front. Neural Circuits 7:95. doi: 10.3389/fncir.2013.00095

van Beugen, B. J., Nagaraja, R. Y., and Hansel, C. (2006). Climbing fiber-evoked endocannabinoid signaling heterosynaptically suppresses presynaptic cerebellar long-term potentiation. J. Neurosci. 26, 8289-8294. doi: 10. 1523/JNEUROSCI.0805-06.2006

van der Steen, J., and Tan, H. S. (1997). Cholinergic control in the floccular cerebellum of the rabbit. Prog. Brain Res. 114, 335-345. doi: 10.1016/s00796123(08)63373-7

van Neerven, J., Pompeiano, O., Collewijn, H., and van der Steen, J. (1990). Injections of $\beta$-noradrenergic substances in the flocculus of rabbits affect adaptation of the VOR gain. Exp. Brain Res. 79, 249-260. doi: 10. 1007/bf00608233

van Swieten, J. C., Brusse, E., de Graaf, B. M., Krieger, E., van de Graaf, R., de Koning, I., et al. (2003). A mutation in the fibroblast growth factor 14 gene is associated with autosomal dominant cerebellar ataxia. Am. J. Hum. Genet 72, 191-199. doi: 10.1086/345488

Wang, Q., Bardgett, M. E., Wong, M., Wozniak, D. F., Lou, J., McNeil, B. D., et al. (2002). Ataxia and paroxysmal dyskinesia in mice lacking axonally transported FGF14. Neuron 35, 25-38. doi: 10.1016/s0896-6273(02)00744-4

Wang, S. S., Denk, W., and Häusser, M. (2000). Coincidence detection in single dendritic spines mediated by calcium release. Nat. Neurosci. 3, 1266-1273. doi: $10.1038 / 81792$
Wang, Y. T., and Linden, D. J. (2000). Expression of cerebellar long-term depression requires postsynaptic clathrin-mediated endocytosis. Neuron 25, 635-647. doi: 10.1016/s0896-6273(00)81066-1

Wylie, K. P., Tanabe, J., Martin, L. F., Wongngamnit, N., and Tregellas, J. R. (2013). Nicotine increases cerebellar activity during finger tapping. PLoS One 8:e84581. doi: 10.1371/journal.pone.0084581

Yamamoto, Y., Lee, D., Kim, Y., Lee, B., Seo, C., Kawasaki, H., et al. (2012). Raf kinase inhibitory protein is required for cerebellar long-term synaptic depression by mediating PKC-dependent MAPK activation. J. Neurosci. 32, 14254-14264. doi: 10.1523/JNEUROSCI.2812-12.2012

Yan, H., Pablo, J. L., and Pitt, G. S. (2013). FGF14 regulates presynaptic $\mathrm{Ca}^{2+}$ channels and synaptic transmission. Cell Rep. 4, 66-75. doi: 10.1016/j.celrep. 2013.06.012

Yi, F., Liu, S. S., Luo, F., Zhang, X. H., and Li, B. M. (2013). Signaling mechanism underlying $\alpha^{2 \mathrm{~A}}$ eadrenergic suppression of excitatory synaptic transmission in the medial prefrontal cortex of rats. Eur. J. Neurosci. 38, 2364-2373. doi: 10. 1111/ejn.12257

Zhu, L., Scelfo, B., Hartell, N. A., Strata, P., and Sacchetti, B. (2007). The effects of fear conditioning on cerebellar LTP and LTD. Eur. J. Neurosci. 26, 219-227. doi: 10.1111/j.1460-9568.2007.05632.x

Zu, T., Duvick, L. A., Kaytor, M. D., Berlinger, M. S., Zoghbi, H. Y., Clark, H. B., et al. (2004). Recovery from polyglutamine-induced neurodegeneration in conditional SCA1 transgenic mice. J. Neurosci. 24, 8853-8861. doi: 10. 1523/jneurosci.2978-04.2004

Conflict of Interest Statement: The authors declare that the research was conducted in the absence of any commercial or financial relationships that could be construed as a potential conflict of interest.

Copyright (c) 2016 Hoxha, Tempia, Lippiello and Miniaci. This is an open-access article distributed under the terms of the Creative Commons Attribution License (CC BY). The use, distribution and reproduction in other forums is permitted, provided the original author(s) or licensor are credited and that the original publication in this journal is cited, in accordance with accepted academic practice. No use, distribution or reproduction is permitted which does not comply with these terms. 